\title{
Mitigating the Urban Heat Island Effect in Megacity Tehran
}

\author{
Sahar Sodoudi, ${ }^{1}$ Parisa Shahmohamadi, ${ }^{2}$ Ken Vollack, ${ }^{1}$ Ulrich Cubasch, ${ }^{1}$ and A. I. Che-Ani ${ }^{3}$ \\ ${ }^{1}$ Institut für Meteorologie, Freie Universität Berlin, Carl-Heinrich-Becker-Weg 6-10, 12165 Berlin, Germany \\ ${ }^{2}$ Resilient Urban Planning + Development (RUPD) GbR, Eichendorffstr. 1, 10115 Berlin, Germany \\ ${ }^{3}$ Department of Architecture, Faculty of Engineering and Built Environment, University Kebangsaan Malaysia (UKM), \\ 43600 Bangi, Selangor, Malaysia \\ Correspondence should be addressed to Sahar Sodoudi; sodoudi@zedat.fu-berlin.de
}

Received 1 May 2014; Revised 18 July 2014; Accepted 20 July 2014; Published 7 September 2014

Academic Editor: Sultan Al-Yahyai

Copyright (c) 2014 Sahar Sodoudi et al. This is an open access article distributed under the Creative Commons Attribution License, which permits unrestricted use, distribution, and reproduction in any medium, provided the original work is properly cited.

Cities demonstrate higher nocturnal temperatures than surrounding rural areas, which is called "urban heat island" (UHI) effect. Climate change projections also indicate increase in the frequency and intensity of heat waves, which will intensify the UHI effect. As megacity Tehran is affected by severe heatwaves in summer, this study investigates its UHI characteristics and suggests some feasible mitigation strategies in order to reduce the air temperature and save energy. Temperature monitoring in Tehran shows clear evidence of the occurrence of the UHI effect, with a peak in July, where the urban area is circa $6 \mathrm{~K}$ warmer than the surrounding areas. The mobile measurements show a park cool island of 6-7 K in 2 central parks, which is also confirmed by satellite images. The effectiveness of three UHI mitigation strategies high albedo material (HAM), greenery on the surface and on the roofs (VEG), and a combination of them (HYBRID) has been studied using simulation with the microscale model ENVI-met. All three strategies show higher cooling effect in the daytime. The average nocturnal cooling effect of VEG and HYBRID $(0.92,1.10 \mathrm{~K})$ is much higher than HAM $(0.16 \mathrm{~K})$, although high-density trees show a negative effect on nocturnal cooling.

\section{Introduction}

Tehran is Iran's largest city, with the highest rate of urbanization. This megacity has a large densely-populated area of $750 \mathrm{~km}^{2}$ (8 million people during the night-time) which has a major impact on human welfare (e.g., air and noise pollution). Both the concentration and the mobility of the population, along with diverse social factors, have transformed the infrastructure and spatial features of the metropolitan area. According to [1], urban development has directly affected Tehran's urban structure, which can be observed in the metropolitan area. Previous investigations of the urban growth processes of Tehran from 1554 onwards show that this city has undergone frequent transformations [2-7]. As an effect of weak urban management, the rural population was attracted to the urban areas, and the growing urbanization led to severe environmental changes (e.g., increasing barren lands).
The urban development of metropolitan areas greatly increases urban environmental problems such as air pollution, higher temperature, traffic congestion and energy consumption. As witnessed in the Tehran metropolitan area, recent increases in the rate of urbanization deteriorate the urban environment. One crucial problem of developing urban areas is that of rising temperature, compared to rural areas, known as the urban heat island (UHI). Emmanuel [8] showed that the UHI is the accumulated warm air over the high density of built-up areas. Asimakopoulos et al. [9] stated that the constructions in urban areas absorb heat during the day and re-emit it after sunset, creating high temperature differences between urban and rural areas. According to Oke [10], the size and structure of the UHI vary in time and space due to meteorological conditions and urban characteristics. There are various causes for the formation of the UHI in the cities. The important factors causing the UHI are the high fraction of built-up areas (Buildings and pavements) as well 
as the lack of vegetation. The main reasons of the formation of the UHI are the low albedo and the high heat capacity of built-up surfaces such as concrete or asphalt, which absorb high amount of the short-wave radiation during the day, this energy is then slowly released during the night as long-wave radiation and leads to higher air temperature in the urban areas. Evapotranspiration describes the transfer of latent heat, from the earth's surface to the air via evaporating water. Urban areas tend to have less evapotranspiration relative to natural landscapes, because of the lack of vegetation. This reduced moisture in built up areas leads to dry, impervious urban infrastructure reaching very high surface temperatures, which contribute to higher air temperatures. With a decreased amount of vegetation, cities also lose the shade and cooling effect of trees. Therefore greenery and using high albedo materials are two strategies, which can mitigate the UHI. The location of city has direct impact on the formation of UHI. Different locations within a given region vary greatly in their temperature, wind conditions, humidity, precipitation, fog, and so forth. Such variations may be caused by differences in distance from the sea, altitude, direction of slopes, and the general topography of the area [11]. Wind and humidity are two main variables, which control the intensity of UHI. The formation of UHI phenomenon depends upon the size and density of the population. Oke [12] has correlated UHI intensity to the size of the urban population. They have a direct relationship in which with higher population, UHI intensity will be increased. Buildings and the density of built-up area modify the wind, the radiative balance, and the temperature conditions near the ground level as builtup area have lower albedo and higher heat capacity comparing to natural surfaces. Therefore, the fraction of builtup area is a relevant factor in formation of UHI [11]. Urban geometry can impede the release of long-wave radiation into the atmosphere. When buildings absorb incoming shortwave radiation, they can re-radiate that energy as longwave energy, or heat. However, at night, due to the dense infrastructure in some developed areas that have low sky view factors, urban areas cannot easily release long-wave radiation to the cooler, open sky, and this trapped heat contributes to the urban heat island.

UHI intensity is greatest under stationary high-pressure systems in stable air and clear-sky condition. It tends to disappear if cloudiness and wind speed increases. The study of Darand and Halabian [13] shows that a dominant strong ridge at the upper level $(850 \mathrm{hPa}$ and $500 \mathrm{hPa}$, Azores high pressure), which is associated with a thermal low pressure on the surface over Pakistan and Iran is the most frequent pattern from April until September in Tehran. This system is accompanied by cloudless sky and a stable boundary layer, which leads to a higher intensity of UHI. The ridge of Azors high pressure in the upper level results in increased concentration of pollution when pollutants expand to the east and are located over north part of Iran. It blocked the convection of surface air, reducing vertical mixing, and thereby increasing air pollutant concentrations near the ground. A subsidence is usually formed under the highpressure systems. The interactions between the low pressures centered at the Pakistan to the north part of Iran with Azores high pressure result in inversion occurrence in Tehran. This pattern is the most frequent and the associated concentration of pollution is very high. More frequent heatwaves and stress are projected over most regions of the densely-populated urban areas for the next decades [14]. Thus, studying the UHI effect and mitigation strategies is one of the major priorities for planning the urban developments in megacities like Tehran.

Greenery is a useful mitigation strategy to reduce the UHI by cooling the air and providing shade and milder outdoor boundary conditions as well as better thermal comfort. Many researchers have studied the effects of greenery such as green roofs [15-18] and high albedo materials $[8,19-24]$ on reducing the local temperature and UHI intensity.

Table 1 summarized the results of some studies on mitigating of UHI in different cities. As it shows, different UHI mitigation strategies have been applied. Reroofing with light colors and planting shade threes indicates the highest cooling effect among the other strategies ( $3 \mathrm{~K}$ ). Applying trees with broad canopies within residential yards led also to $2,4 \mathrm{~K}$ temperature reduction, although other studies indicate a cooling effect between $0,5-1,6 \mathrm{~K}$, which show the higher cooling effect of shade trees in comparison to planting ground level vegetation or using high albedo materials.

The UHI has a direct impact on human health due to higher temperature, which is responsible for the morbidity and mortality risks. Both the planning and policies for urban environmental sustainability in the metropolitan area of Tehran are impossible without a temperature mitigation policy. Mesoscale air flows such as sea breezes, mountain, valley winds (slope-winds), and the urban heat-island circulations partly control the local weather and pollutant transport worldwide.

The main aim of this paper is to study the effects of greenery in connection with the high albedo materials in reducing the UHI effect in the metropolitan area of Tehran and finding a mitigation policy for adapting the infrastructure against the microclimate changes. However, there is a lack of research in the context of Tehran UHI. In this paper, we have applied satellite data, mobile measurements and permanent stations in order to study the UHI of Tehran.

The effect of greenery and high albedo materials on local climate in the 6th district of Tehran has been simulated by using the microclimate model ENVI-met [33] for a typical hot summer-day in Tehran. The simulations were carried out for current situations as well as under three different mitigation strategies.

\section{Case Study Area}

Tehran $\left(35^{\circ} 42^{\prime} \mathrm{N}, 51^{\circ} 25^{\prime} \mathrm{E}\right)$, the fastest growing city in Iran, with around 8 million inhabitants and an area of $750 \mathrm{~km}^{2}$ is one of the largest cities in the world located on the southern side of the Alborz mountain range and is limited to the highlands and mountains in the North and East and to the flat plains and desert in the South and West (Figure 1). The average annual rainfall is approximately $230 \mathrm{~mm}$, with most precipitation falling in autumn and winter months. Due to 
TABLE 1: A review on maximum temperature in different cities, UHI mitigation methods, and their cooling effects as well as the percentage of energy saving of different UHI mitigation strategies in different regions. Planting shade threes shows the highest cooling effect ( 3 K) in Los Angeles.

\begin{tabular}{|c|c|c|c|c|c|}
\hline Reference & Method & $\begin{array}{l}\text { Maximum } \\
\text { temperature }\end{array}$ & $\begin{array}{l}\text { Reduction in } \\
\text { temperature }\end{array}$ & Reported savings & City/region \\
\hline$[19]$ & $\begin{array}{l}\text { Reroofing: lighter colors } \\
\text { and planting shade trees }\end{array}$ & - & $3 \mathrm{~K}$ & $10 \%$ & Los Angeles \\
\hline$[25]$ & $\begin{array}{l}\text { Replacing urban areas } \\
\text { with grass land }\end{array}$ & $\begin{array}{l}30^{\circ} \mathrm{C} \text { (surface } \\
\text { temperature) }\end{array}$ & $1.6 \mathrm{~K}$ & - & Hong Kong \\
\hline$[26]$ & $\begin{array}{c}\text { New park nearby } \\
\text { commercial area }(1 \mathrm{~km} \\
\text { downwind })\end{array}$ & $\begin{array}{c}40,3^{\circ} \mathrm{C} \text { (surface temp. } \\
\text { Of grass field) }\end{array}$ & $1.5 \mathrm{~K}$ & $15 \%$ & Tokyo \\
\hline$[27]$ & $\begin{array}{c}\text { Reducing anthropogenic } \\
\text { heat }\end{array}$ & - & $1.2 \mathrm{~K}$ & $4-40 \%$ & Tokyo \\
\hline$[28]$ & $\begin{array}{l}\text { Large scale increase in } \\
\text { surface albedo and } \\
\text { vegetative fraction }\end{array}$ & $37^{\circ} \mathrm{C}$ & $0.5-1.5 \mathrm{~K}$ & $\begin{array}{c}10 \% \\
\text { (at peaks) }\end{array}$ & USA \\
\hline [29] & $\begin{array}{l}\text { Building planting (walls } \\
\text { and roofs) }\end{array}$ & $28,95^{\circ} \mathrm{C}(1 \mathrm{~m})$ & $1.3 \mathrm{~K}$ & $25 \%$ & \\
\hline$[30]$ & $\begin{array}{l}\text { Trees with broad } \\
\text { canopies within } \\
\text { residential yards }\end{array}$ & $32^{\circ} \mathrm{C}$ & $2.4 \mathrm{~K}$ & 1.24 mio l Water/year & Phoenix \\
\hline$[30]$ & $\begin{array}{l}\text { Roofs with high albedo } \\
\text { and vegetation }\end{array}$ & $28,2^{\circ} \mathrm{C}$ & - & $24,14,45 \%$ & $\begin{array}{c}\text { Barcelona, Palermon, } \\
\text { Cairo }\end{array}$ \\
\hline$[31]$ & $\begin{array}{l}\text { Low albedo, building } \\
\text { geometry } \rightarrow \text { wind effects }\end{array}$ & $34,4^{\circ} \mathrm{C}$ & $0.7 \mathrm{~K}$ & - & Singapore \\
\hline
\end{tabular}

TABle 2: An overview on climate data from the station TehranMehrabad (MHR), 1980-2009.

\begin{tabular}{lc}
\hline Annual mean temperature & $17.5^{\circ} \mathrm{C}$ \\
Annual mean precipitation & $230 \mathrm{~mm}$ \\
Annual mean humidity & $40 \%$ \\
Annual most frequent wind direction & West \\
Mean number of clear days & 318 \\
Mean number of inversion occurrences & 251 \\
\hline
\end{tabular}

high elevation, aridity and latitude, the city experiences four seasons. Climate can be extremely hot in the summer (with midday temperatures ranging between 30 to $40^{\circ} \mathrm{C}$ ), and cold in winter when night time temperatures can be below the freezing point. Local precipitation is absent for 6 months of the year on the low lying areas. Synoptic scale low pressure systems that originate from the Mediterranean propagate over the region in spring and autumn, while in winter the southward extension of the Siberian high pressure system can advect cold temperatures over the Iranian Plateau. A large scale easterly flow dominates the area in the summer, thought to be associated with a circulation pattern named "the winds of 120 days" caused by a thermal low over Pakistan [34]. Therefore aside from the summer when large scale flow is easterly, a westerly direction is preferred at other times but is thought to be modified by the mountains. Table 2 shows the annual mean temperature, humidity, precipitation and other variables from 1980 to 2009 in the station Tehran-Mehrabad (MHR). Table 2 demonstrates the ideal condition for UHI formation in Tehran (annual mean humidity of 40\%, 318 clear days per year).

Air pollution in Tehran is the biggest environmental problem and determined even by its geographic position. The Alborz mountain range, with an average width of about $100 \mathrm{~km}$. [35], acts as an almost continuous wall. The altitude of Tehran is between 900 to 1,700 meters above sea level [36]. There is a major difference in altitude between the northern and southern parts of the city which has a significant impact on the characteristics of urban spaces in the Tehran metropolitan area. In semiarid regions such as Tehran, the climatic conditions regularly lead to cloudless weather conditions with weak winds which can approximately be considered "ideal" as defined by Oke [37]. This is especially true during summer when synoptic influences are reduced and depression disturbances are less frequent. The measurements of Zawar-Reza et al. [38] in Tehran confirm the typical diurnal cycle of an unstable, turbulent planetary boundary layer during the day, where downward momentum flux is high and hence wind speeds are increased. Towards the evening, a stable boundary layer with decreased wind speeds develops and keeps on growing throughout the night due to long-wave radiative loss producing a sensible heat flux directed away from the surface. This is important, as it emphasises the high potential of a poorly ventilated nocturnal boundary layer that contributes to urban heat island and elevated pollution levels.

Several national studies have investigated trends in averages of maximum and minimum temperature and precipitation in Iran. Alijani [39], Jahadi Toroghi [40], and Rasooli [41] have previously worked on some selected stations. 


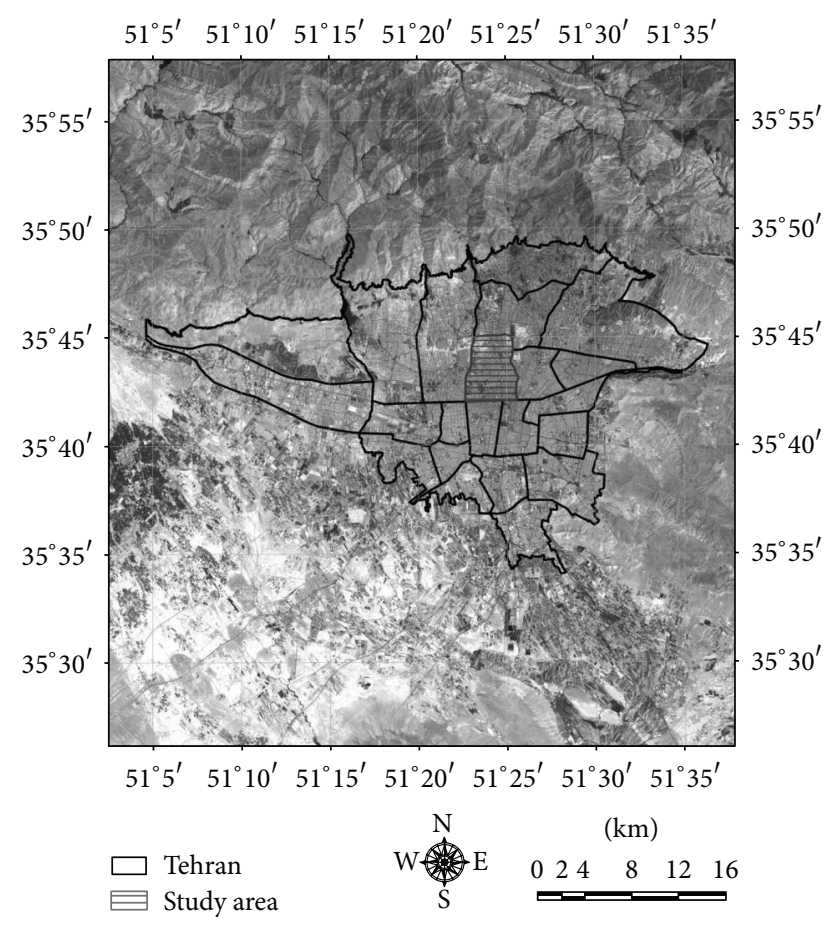

Figure 1: 22 urban districts in mega city Tehran. The dashed area shows the 6th urban district.

Rahimzadeh and Asgari [42, 43] using a set of high-quality records showed significant trends for minimum and maximum temperatures and precipitation over most of the Iranian territory for the period 1951-1997. They found increasing trends in minimum temperature for all stations under study except Oroomieh, located in the northwest of the country. The result for Oroomieh was confirmed by Pedram et al. [44]. In Iran, the outcome of the global warming is the increasing frequency of extreme events such as heat waves, torrential rains, or prolonged intensive droughts, hence increasing danger and harm to the built environments and people. Rahimzadeh and colleagues [45] examined extreme temperature and precipitation as indicative climatic variables to determine recent climatic changes over Iran. They present the results from 27 synoptic stations which have been quality controlled and tested for homogeneity and have less missing data. For each station, 27 indicative climatic indices were calculated. Marked negative trends for indices like frost days (FD), ice days (ID), cool days (TX10p), cool nights (TN10p), and diurnal temperature range (DTR) were found over most regions of Iran. Conversely, positive trends were found for summer days (SU25), warm days (TX90p), and tropical nights (TR20) over most regions of the country. For indices such as Cold Spell Duration Index (CSDI) and Warm Spell Duration Index (WSDI), both positive and negative trends were obtained. Another study on coastal regions in Iran [46] indicates that temperature indices are absolutely consistent with warming. Warm nights, hot days, and hot day and night frequencies increased, while cold spell and cool day and night frequencies declined. Tagavi and Mohammadi [47] have also confirmed the decrease of frequency of cold and increase of warm events during the past years in Iran.

The analysis of intensity and frequency of extreme events is a very important step in the process of planning and designing the urban areas especially in the semiarid climate of Iran. In these areas climate is very fragile and a sudden change may cause destructive outcomes [48]. Beside the more frequent heat waves, the rapid urbanization growth, and the related UHI will also lead to higher temperature in the future.

In Tehran, the change of land use from natural surfaces to new built structures during recent decades and expansion of the city size, results in changes of the natural surface of the earth. The changes of materials that cover the earth's surface affect the absorption of solar energy and the changes of the shapes of the earth's surface. Moving the large number of population from the suburbs to the fast growing Tehran urban area caused acceleration of urbanization, increasing the city size and the density of built-up area, respectively. In Tehran, the local winds are often not strong enough to circulate the air. Around $70 \%$ of the winds in Tehran have speeds below 6 knots and have little impact on air circulation in large built-up areas. Only $30 \%$ of the winds, which usually blow in spring, late summer and early autumn, have speeds of more than 10 knots and can clear the air [49]. The problem, however, is that the major winds blow from the west, south, and south-east, where most of the industries are located. Rather than cleaning the air, they can pollute the air further. Only the winds from the northern mountains, with their limited impact, blow in the right direction.

The on-going climate change is predicted to yield a growing number of extreme climate events which will increase in both intensity and frequency. It will have a direct impact on population health, morbidity, and mortality. Many studies have previously shown that the elderly in a society are among the most vulnerable to heat waves [50]. Over the past three decades, Tehran has experienced warmer summers and high amounts of heat-related mortality. Ahmadnezhad et al. [32] showed that the total excess mortality during the last 17 heatwaves in Tehran, which was about 8.9 deaths per heat period. Figure 2 shows the average temperature maximum of all recorded heat waves in Tehran from 2001 to 2011. Table 3 shows also the length of the each heat wave, the number of death during its period as well as the excess mortality in percent [32] for five different categories (all mortality causes, elderly people $\geq 65$ year, cardiovascular causes, cerebrovascular causes, and respiratory causes). As Figure 2 shows, during all heat waves the average maximum temperature exceeds $38^{\circ} \mathrm{C}$ in the whole period. The largest death ratio (1005 death in 8 days) and also excess mortality (19.2\%) was occurred in 2009' wave, which was the hottest wave with the average of maximum daily temperature of $40^{\circ} \mathrm{C}$ (Table 3). Mortality for $65+$ years had also significant excess mortality. The largest number of deaths $(65+)$ also happened in heat wave of 2009 and was about $17.7 \%$ related to the total deaths of 558. The total number of death during all heat waves in the last decade was about 14475 , which has a mean value about 851 deaths per heat wave. The people older than 65 years are the most affected category by heat 
TABLE 3: Heat waves in Tehran from 2001 to 2011. Em indicates the excess mortality in percent and NofD indicates the number of death from 5 categories: all mortality causes, elderly people $\geq 65$ years, with cardiovascular, cerebrovascular, and respiratory causes [32].

\begin{tabular}{|c|c|c|c|c|c|c|c|}
\hline \multirow{2}{*}{ Year (number of heat waves) } & \multirow{2}{*}{ Length in days } & \multicolumn{2}{|c|}{ All causes } & \multirow{2}{*}{$\begin{array}{c}>65 \text { years } \\
\text { NofD }\end{array}$} & \multirow{2}{*}{$\begin{array}{c}\text { Cardiovascular } \\
\text { NofD }\end{array}$} & \multirow{2}{*}{$\begin{array}{c}\text { Cerebrovascular } \\
\text { NofD }\end{array}$} & \multirow{2}{*}{$\begin{array}{c}\text { Respiratory } \\
\text { NofD } \\
\end{array}$} \\
\hline & & $\operatorname{Em}(\%)$ & NofD & & & & \\
\hline $2001(1)$ & 4 & 6.1 & 452 & 240 & 181 & 49 & 18 \\
\hline $2001(2)$ & 4 & 10 & 493 & 246 & 211 & 46 & 25 \\
\hline $2001(3)$ & 3 & 11.6 & 327 & 157 & 143 & 18 & 13 \\
\hline $2002(1)$ & 6 & 9.8 & 692 & 366 & 308 & 42 & 18 \\
\hline $2002(2)$ & 7 & 11.6 & 524 & 275 & 204 & 35 & 18 \\
\hline 2003 & 1 & 0.8 & 1704 & 873 & 721 & 164 & 75 \\
\hline 2005 (1) & 11 & 3.2 & 1377 & 744 & 504 & 129 & 104 \\
\hline $2005(2)$ & 5 & 14.6 & 658 & 370 & 238 & 64 & 38 \\
\hline 2006 (1) & 7 & 15.8 & 881 & 466 & 303 & 61 & 54 \\
\hline 2006 (2) & 5 & 3.9 & 587 & 319 & 203 & 48 & 39 \\
\hline 2006 (3) & 5 & 11.3 & 619 & 322 & 173 & 64 & 46 \\
\hline $2006(4)$ & 5 & 11.7 & 885 & 468 & 293 & 77 & 60 \\
\hline 2008 (1) & 7 & 6.4 & 868 & 482 & 343 & 49 & 64 \\
\hline 2008 (2) & 3 & 5.6 & 392 & 208 & 147 & 24 & 40 \\
\hline 2009 & 8 & 19.2 & 1005 & 558 & 401 & 73 & 76 \\
\hline 2010 & 14 & 2.7 & 1658 & 939 & 613 & 109 & 143 \\
\hline 2011 & 11 & 8.9 & 1353 & 745 & 476 & 103 & 112 \\
\hline
\end{tabular}

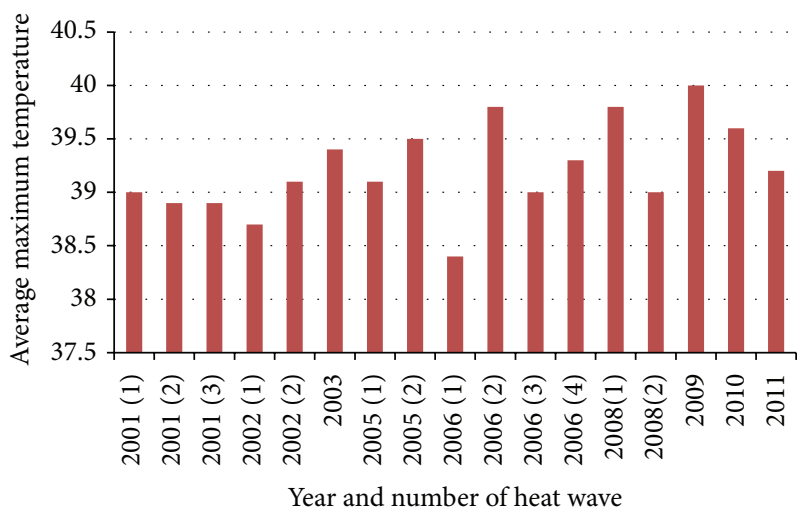

Figure 2: The average maximum temperature of heat waves in Tehran from 2001 to 2011. The number in parentheses indicates the order of the heat wave during the year. As it has been shown, three heat waves affected Tehran in 2001.

stress (53\%). People with cardiovascular problems are in the second place (37\%), although the percentage of death due to cerebrovascular and respiratory causes is under $10 \%$. Thus, reducing the temperature through mitigating of the UHI is an important key for the urban and landscape planners in Tehran in order to obtain better conditions of human comfort and human health.

Although Tehran has 22 districts (Figure 1), the simulation of the effects of UHI mitigation strategies (greenery and high albedo surface materials) on local climate for the whole of Tehran is not possible due to the limitations of the microclimate model ENVI-met. As a result, the 6th urban district of Tehran was selected for simulations. The selection of this urban district is due to its location, which is near the
TABLE 4: Fraction of impervious surface area and vegetation in the 6th urban district in Tehran.

\begin{tabular}{lcc}
\hline Type of land use & $\begin{array}{c}\text { Percentage within 6th } \\
\text { urban district }\end{array}$ & Area (h) \\
\hline $\begin{array}{l}\text { Impervious surface area } \\
\text { (pavement, buildings) }\end{array}$ & $97.37 \%$ & 2087.52 \\
$\begin{array}{l}\text { Vegetation (tree canopy and } \\
\text { ground level vegetation) }\end{array}$ & $2.4 \%$ & 51.57 \\
\hline
\end{tabular}

centre of Tehran and surrounded by the main urban axes of the city and its traffic congestion. This urban district has the highest concentration of important business centres which are an important function of the city and is one of the most polluted districts in Tehran. The topography of the district with North-South and East-West slopes have led to the unique diversity of the urban space and its features, especially in the northern parts of the district, which contributes to an unequal distribution of pollution and provides a warm air canopy over the central part. The average administrative density of the 6th urban district is about 103 persons per hectares. With an area of 2149 hectares, the latter is about 3.5\% of Tehran's area, and had a population of 2,24,097 people in 2006, which is also about $3 \%$ of the city's population. The main land uses of the zone included $34.9 \%$ residential, $27.6 \%$ transport, $22.4 \%$ public welfare services, $8.3 \%$ general activities, $2.4 \%$ military, $2.4 \%$ vegetation and finally $0.88 \%$ urban utilities [51]. The average height of the buildings is usually less than that of the other large cities of the world (4-5 story building and the mean sky view factor is about 0,5 [52]. Table 4 shows the percentage of impervious surface area and vegetation in the 6 th urban district [53]. This district with around 98 percent of built-up area has no potential to act as a green environment. 


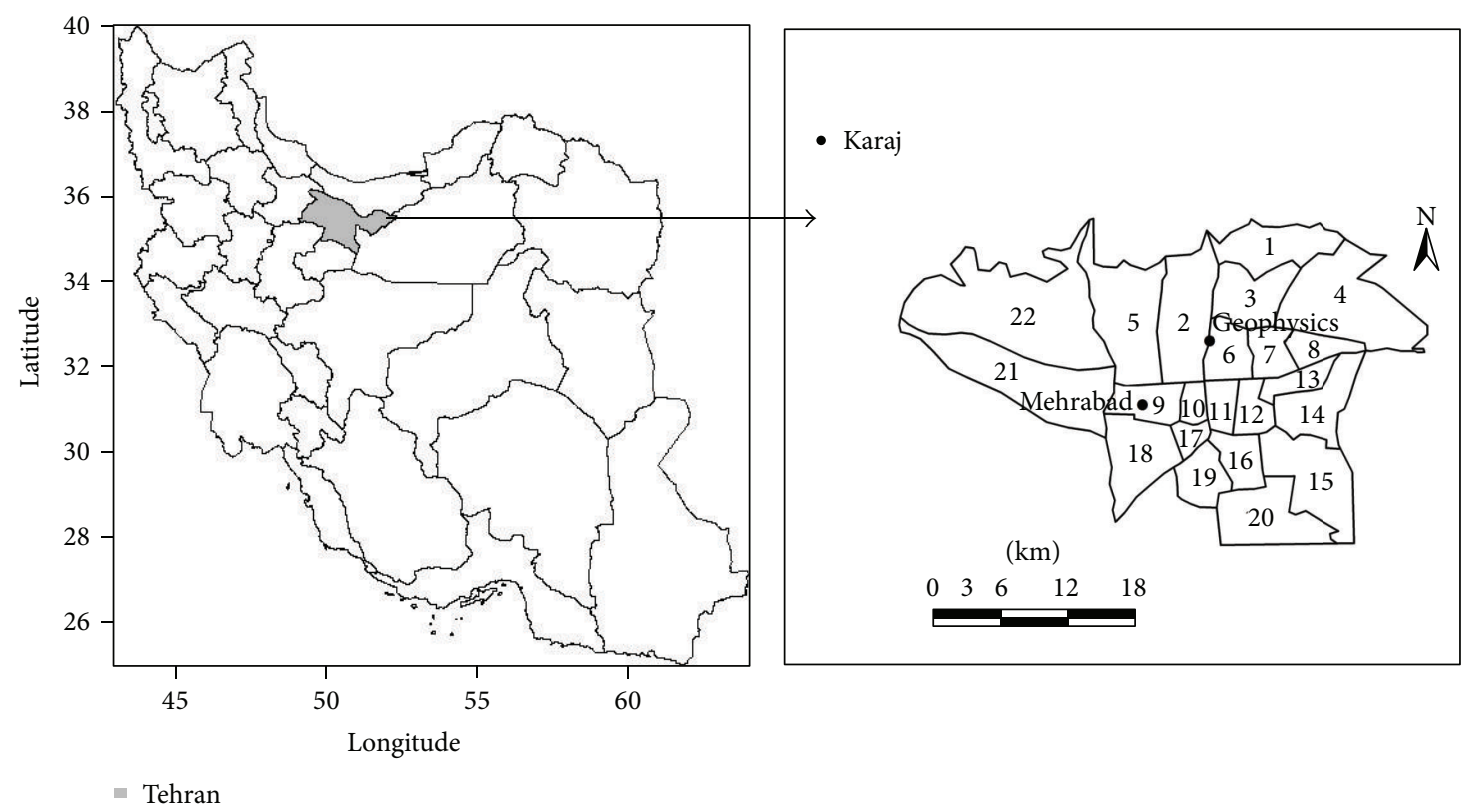

FIgURE 3: The location of Tehran and three meteorological stations Geophysics (GEO), Mehrabad (MHR), and Karaj.

The roofs have a total area about $643 \mathrm{~h}$ and can be used as free spaces to mitigate the UHI regarding different methods. Greenery constitutes $51.57 \mathrm{~h}$ of this urban district, which indicates circa $2.21 \mathrm{~m}^{2}$ of green space per capita, although the amount recommended by the United Nations is about 20-25 $\mathrm{m}^{2}$ [53]. The average per capita green space within an urban area of $2.21 \mathrm{~m}^{2}$ is very low compared with its average in other Asian cities such as $10 \mathrm{~m}^{2}$ in Singapore, $7 \mathrm{~m}^{2}$ in Tokyo, and $12.5 \mathrm{~m}^{2}$ in Shanghai [54].

\section{Methodology}

In the first part of this study, the characteristic of the UHI in Tehran has been analyzed using measured $2 \mathrm{~m}$ temperature data from synoptic stations and mobile measurements in urban and rural areas as well as the derived land-surface temperature from Landsat. The second part of the study deals with UHI mitigation strategies (e.g., high albedo materials and greening). The influence of high albedo materials and greening on $2 \mathrm{~m}$ temperature and the relative humidity of the 6th urban district of Tehran have been studied and their application as mitigation strategies has been discussed.

3.1. THE UHI Characteristic in Tehran. All of the meteorological data used for the UHI analysis were obtained from the Islamic Republic of Iran Meteorological Organization (IRIMO). The data include time series of daily mean, maximum and minimum $2 \mathrm{~m}$ temperatures, as well as the 3 hourly values for three stations. These stations (Figure 3) include MHR (located at Mehrabad Airport, representing the urban station with an altitude of 1,190.8 m), GEO (located at Teheran Geophysics Institute, representing another urban station with an altitude of $1,418.6 \mathrm{~m}$ ), and KRJ (located at Agriculture
Institute in Karaj, representing a rural station with an altitude of $1,312.5 \mathrm{~m}$ ). The average altitude of Tehran is $1,200 \mathrm{~m}$, with an $800 \mathrm{~m}$ altitude difference between its lowest and highest points. In this study, two urban stations, MEHR (lower than rural station) and GEO (higher than rural station), have been considered in order to show the effect of urbanization as well as the station elevation of the air-temperature difference between urban and rural areas, and thus no temperature correction has been attempted. The station Tehran Mehrabad has the longest record from 1951 till 2008. The stations KRJ and GEO were installed in 1985 and 1991, respectively. Thus, the time range of 1991-2009 was determined for the investigating of the UHI due to the availability of the data from GEO.

The stations used in the study are at different altitudes. The difference in minimum temperature serves as the primary indicator of the UHI intensity because the difference is normally most pronounced at night [55]. Mehrabad station (MHR) is located in western part of Tehran where the airport is situated. The Geophysics station (GEO) is located in the 6 th urban district and has been used to calibrate the mobile instruments. In Karaj station (KRJ), the major land use is agriculture. At Mehrabad, Geophysics, and Karaj stations, the annual maximum and minimum dry-bulb $2 \mathrm{~m}$ temperatures indicate a slow upward trend during the period 1991-2009 (Figure 4).

It is clear that stations GEO and KRJ have very similar characteristics during the day, which is shown as time-series of annual mean maximum temperatures. The MHR station with a lower altitude of between 300 and $400 \mathrm{~m}$ shows the highest values. It indicates that the important factor to determine the daily temperature is the altitude difference. The annual mean minimum temperature of these three stations has also been shown in Figure 4. The similarity between GEO 


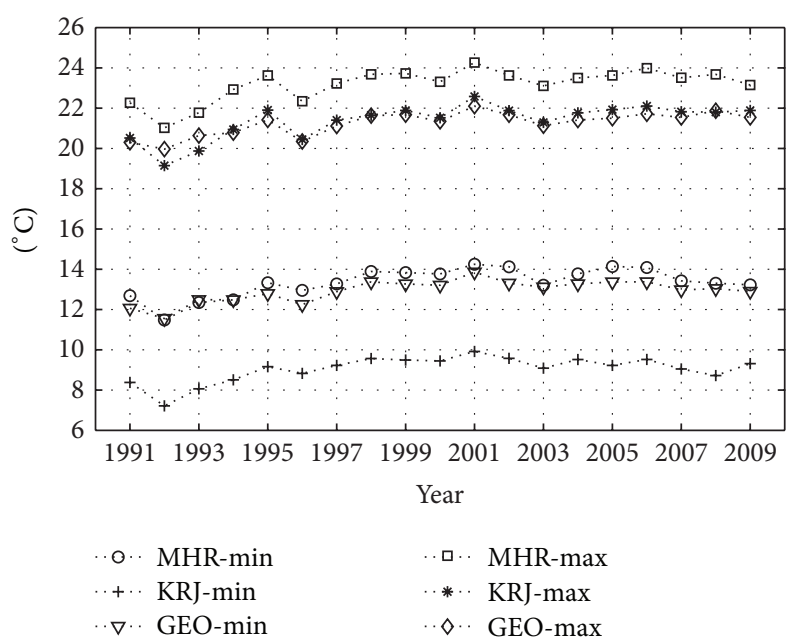

FIgURE 4: The annual mean, maximum, and minimum dry-bulb $2 \mathrm{~m}$ temperatures of stations GEO, MHR and KRJ during the period 1991-2009.

and MHR is much more than between GEO and KRJ (urban and rural), although they have only a circa $100 \mathrm{~m}$ difference in altitude. It indicates that the urbanization and built-up areas are important factors to determine the temperature at night (3-4 hours after sunset). As it has been shown in Table 2, the frequency of occurrence of frontal systems and precipitation is about $12 \%$. In order to characterize the UHI, we use only the cloudless days without any precipitation/frontal passage in the period of 1991-2009, when the UHI or urbaninduced warming is the strongest [56]. The investigation of a 19-year period of urban (MHR and GEO) and rural (KRJ) minimum temperatures in Tehran clearly shows the temperature difference between these two areas (Figure 5). The largest UHI intensity was in the summer (July). For MHR-KRJ and for GEO-KRJ; July has a peak UHI value of 5.8 and $6.1^{\circ} \mathrm{C}$, respectively. For both MHR-KRJ and GEOKRJ, the smallest UHIs exist in winter, with minimum values in December, 2.88 and $2.17^{\circ} \mathrm{C}$, respectively. The finding of a stronger UHI in summer is/in contradiction with Zhou and Shepherd's [57] and Kim and Baik's [58] investigation of UHI in Atlanta and Seoul. Zhou and Shepherd found the strongest UHI intensity in Atlanta in spring, while Kim and Baik found stronger UHIs in the winter and fall, rather than the spring. However, Kim and Baik did note that the trend in UHI over a 24-year period was greatest during the spring.

The emergence of spring vegetation may result in a larger albedo gradient with the urban area, which would cause a larger UHI. According to Unger et al. [59], the seasonal UHI pattern may be determined to a high degree by urban surface factors. Cloudiness and wind speed may play a negative role in the development of UHI. Liu et al. [60] stated that the seasonal UHI variation tended to be negatively correlated with the seasonal variation of relative humidity and vapour pressure. Tehran is located in the semiarid, continental climate. It has hot and dry summers, and cold winters. The precipitation period is from November to May, followed by a dry period from May to October with rare or

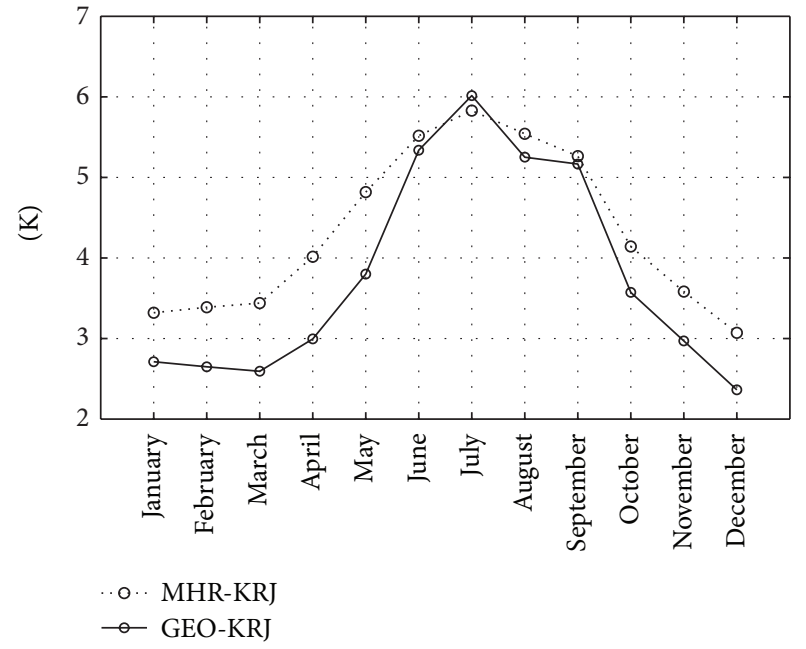

FIgURE 5: The difference between minimum temperatures of stations MHR and GEO and the rural station KRJ in the period of 19912009.

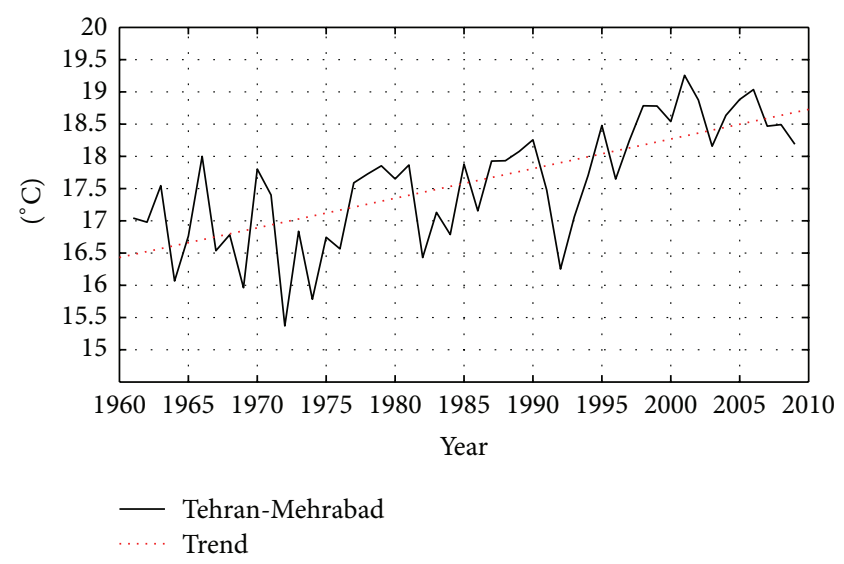

Figure 6: Mean annual $2 \mathrm{~m}$ Temperature from 1951-2009 in Tehran Mehrabad station.

little precipitation [61]. The seasonal UHI pattern may be affected by seasonal cloudiness in Tehran. The analysis of mean wind speed from 1953 to 2006 in the Tehran Mehrabad station shows that, in this period, the percentage of calm wind increased and led to a reduction of the mean wind speed [62]. Figure 6 shows the mean annual $2 \mathrm{~m}$ temperature from 1951 to 2009 in the Tehran Mehrabad station. As has been shown, the mean annual temperature increased in this 58 year period. The red line shows the positive temperature trend. The rapid increase of $2 \mathrm{~m}$ temperature in Tehran is due to the rapid growth of the population, which led to an increase in built-up areas with low albedo materials and reduced sky view factors. The number of private cars (per 1,000 people) changed from 5 in the year 1956, to 90 in the year 2006 [62]. Besides this quick change in the number of cars being used, the energy consumption and resulting heat from new built-up areas caused the high concentration of air pollutants in Tehran, which absorbs and reemits long-wave radiation and leads to stronger UHI. A comparison between Mehrabad/GEO and 
Karaj in terms of climatic changes and physical development over the period 1991-2008 reveals that the warming in the urban stations is strongly attributed to the increase in the UHI effect.

3.2. Satellite Images. A satellite image was employed to map out the surface temperature in Tehran, to verify local boundaries of urban and rural areas, and to identify hot spots. A Landsat $7 \mathrm{ETM}^{+}$satellite image obtained on 18 July 2000 (due to limitations of the data in Tehran, only this map was available) with spatial resolution of $15 \mathrm{~m}$ in panchromatic band, $30 \mathrm{~m}$ in 6 visible bands, and $60 \mathrm{~m}$ in thermal band was selected, which was provided by the Iranian Space Agency. The image was radiometrically calibrated and geometrically corrected to obtain the detected radiance data. The detected radiance in thermal band was converted to the equivalent surface temperatures using Planck's blackbody formula. Land cover was classified into several classes using the visible, NIR, and SWIR bands. Instead of ambient temperature, the relative surface temperature can be seen from the satellite image. Within the urban canyon canopy layer in the morning or where wind velocity is low, the surface temperature is determined by adjacent surfaces. Thus, the surface temperature map is acceptable for studying the UHI effect in the early part of the day. The reason for using the satellite images is to acquire the urban-rural visual difference at mesoscale rather than to provide absolute values. Time limitations and the lack of a traverse observational approach to ascertain the UHI intensity limit the use of satellite imagery for exploring UHI. Thus, in order to trace the gradual influence of urbanization on local climate, historical weather data were examined.

Figure 7 shows the first observation of the clear surface temperature boundary that coincides with land use in Tehran and Urban District 6. The warm regions, represented by the red and yellow colours, are mostly located in the central, western, and southern parts of Tehran where the central business district (CBD), industrial area(s), and airport are located, respectively. On the other hand, the northern parts of Tehran are relatively cool, shown in green. This is due to the concentration of greenery and water bodies as well as having less impact from the high-density urban developments. The contrast between urban and rural areas hints at the prevalence of the UHI effect in Tehran, although the satellite image only provides the instantaneous observation during the daytime.

The surface temperature of study area (Urban District 6) reveals some areas with either high or low surface temperature. In Figure 7, Region 1 experiences the highest temperature during the daytime, especially in the north and west parts of the region mainly because of the lack of extensive landscape and because it is close to the two main highways (Hemat in the north and Chamran in the west). Similarly, higher temperatures are observed in the east and northeast parts of Region 2. This is also reasonable since the exposed runway absorbs a lot of incident solar radiation during the daytime and incurs high surface temperature. It might be due to the bus station terminal located nearby. Regions 5 and 6 are close to the central business district of Tehran and neighbour with the Enghelab Street, the most crowded

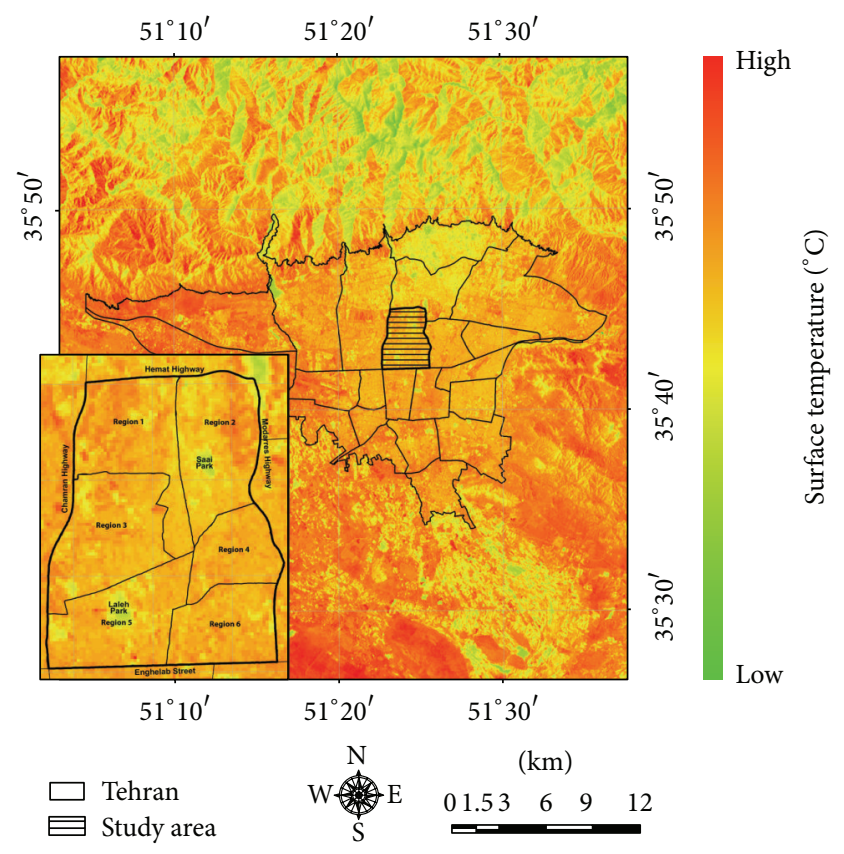

Figure 7: : Land surface temperature from Landsat on July 18th 2000.

street. In Regions 2 and 5, the effects of two parks (Saai and Laleh) on surface temperature can be observed (park cool island, PCI). The worst scenarios occur in some parts in northeast and northwest of the district. The satellite image shows a broad picture of temperature variance between urban and rural areas. This indicates the occurrence of UHI effect during daytime in Tehran. The hot spots are observed on hard surfaces in the urban context, since hard surfaces absorb lots of solar radiation and cause high surface temperatures which contribute to the increase in the ambient temperatures.

3.3. Mobile Measurements. The 3 hourly meteorological data derived from the local weather station network can remedy the temporal limitation of the satellite images, but, due to the low number of stations in the urban area, it is difficult to recognize the spatial distribution of $2 \mathrm{~m}$ temperature, especially the $2 \mathrm{~m}$ temperature difference between different points which are located in parks and green areas as well as within or between residential developments. As a result, field survey was carried out in order to complete the observations derived from the satellite image and the weather stations. The field survey was done by persons holding the mobile measuring instrument "Lutron LM-800" at 31 designated locations $2 \mathrm{~m}$ above the ground throughout the 6th urban district of Tehran on a hot summer day, 18 July 2009. This professional measuring instrument has a tiny bone shape and is lightweight, small in size, and is suitable for handling with one hand. The instrument has a resolution of $0.1^{\circ} \mathrm{C}$ and the accuracy of $\pm\left(1 \% \mathrm{rdg}+1^{\circ} \mathrm{C}\right)$.

Before starting measurement, the instruments were calibrated against the weather station "Geophysics," which is located in the 6th urban district. The measurements were 


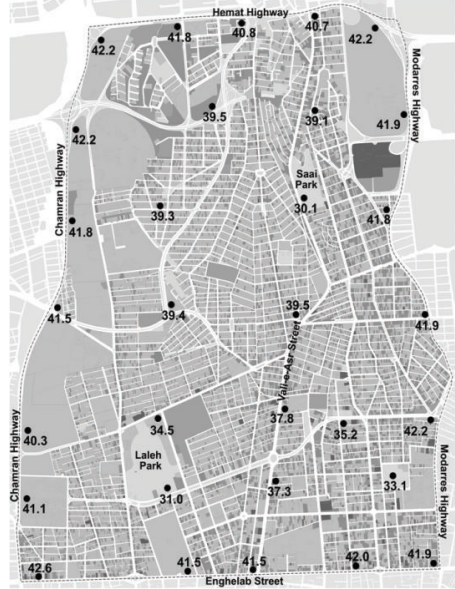

(a)

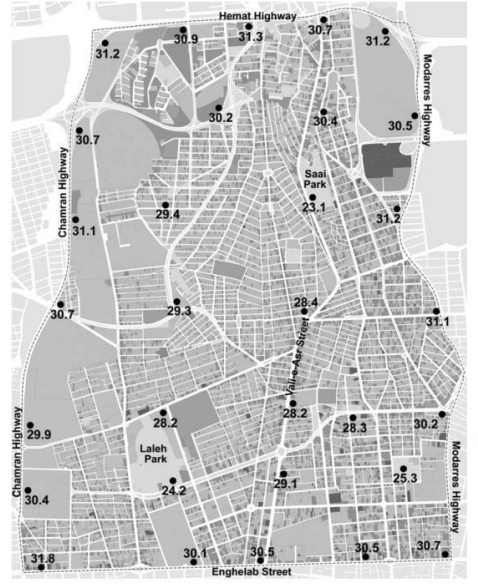

(b)

FiguRE 8: Mobile measurement in 6th urban district on July 18th 2000, (a) 13:00-15:00 h; (b) 21:00-23:00 h.

carried out by 3 persons, every 5 minutes. The measurements covered different land uses such as parks, residential, commercial, and industrial areas and public services. They were taken simultaneously at all locations in two sessions: the day session between 13:00 and 15:00 h local time and the night session between 21:00 and 23:00 h. For every particular point, the temperature was calculated by averaging three measurements in the same point. It should be noted that, during the measurements, the instruments were shaded.

The temperature distribution at various locations during the night- and day-times is shown in Figure 8. The highest temperatures were observed mainly in industrial and commercial land uses in the south of the district. The industrial land uses generally have low-rise buildings and the high temperature recorded in these areas is related to the extensive usage of low albedo material in the buildings. The high temperature of commercial buildings is related to the use of concrete and dark stone which absorb most of the solar radiation and later release it into the atmosphere. A maximum daily temperature of $42.6^{\circ} \mathrm{C}$ was observed at the industrial land use located in Enghelab Street. The other areas, which had high temperatures $\left(40-42.6^{\circ} \mathrm{C}\right)$, included mainly the west, east, and north borders of the district where the main highways (Chamran, Modares, and Hemat) are located with high traffic congestion, air pollution, and the lack of vegetation cover. The lowest temperatures of $30.1^{\circ} \mathrm{C}$ and $31^{\circ} \mathrm{C}$ were observed in the Saai and Laleh parks (park cool island, PCI). The central part (high density builtup area) showed lower temperatures than the borders of the district. Smaller sky view factor in this region leads to cooler temperatures than the border area. The night-time temperatures varied between $23.1^{\circ} \mathrm{C}$ and $31.8^{\circ} \mathrm{C}$, and it was found that the central part of the district was around 6$7^{\circ} \mathrm{C}$ hotter than the other locations with greenery. This also indicates the centre of the nocturnal UHI, which has shifted from the borders during the daytime to the central area. The high density of buildings and air conditions (anthropogenic heat) in this area leads to higher nocturnal temperatures. The average temperature of $24.2^{\circ} \mathrm{C}$ was recorded in Laleh Park, the large green area located in this district. The maximum temperature of $31.82^{\circ} \mathrm{C}$ was still noted in industrial land use in Enghelab Street. The results of the field survey shows clear evidence of higher temperatures in the city centre than in the green areas in 6th urban district of Tehran, with the high density residential, commercial, and industrial land uses showing around $6-7^{\circ} \mathrm{C}$ higher temperatures.

\section{Numerical Modelling with ENVI-Met}

ENVI-met [33], a three-dimensional numerical model, was employed to study the basic pattern of the urban effects on microclimatic factors such as temperature, wind speed, and humidity in the current situation of the 6th district of Tehran, as well as under some UHI mitigation strategies. ENVImet is a tool for studying the surface-plant-air interaction at microscale. We applied the 3.99.2.8 version to simulate the microclimate in this study. A user-specified area input file defining the three-dimensional geometry of the investigated area is required for each ENVI-met simulation. It includes geocoded building dimensions (e.g., width and height), soil (e.g., type and texture), surface (e.g., concrete or asphalt), and vegetation types. The numerical model simulates aerodynamics, thermodynamics, and the radiation balance in complex urban structures. It is designed for microscale with a typical horizontal resolution from 0.5 to $10 \mathrm{~m}$ and a typical time-frame of 24 to 48 hours with a time step of 1 to 10 secs. This resolution allows small-scale interactions between individual buildings, surfaces, and plants to be analyzed. Typical domains are between a single street canyon up to a few hundred meters. The model is designed for microscale modeling due to the domain's and the model's time limitations. Despite these limitations, ENVI-met has been widely applied in different studies on UHI mitigation, which demonstrates the model's capability. Ng and colleagues [54] used ENVI-met to estimate the cooling effects of greening in a densely built-up area in Hong Kong. They found out 

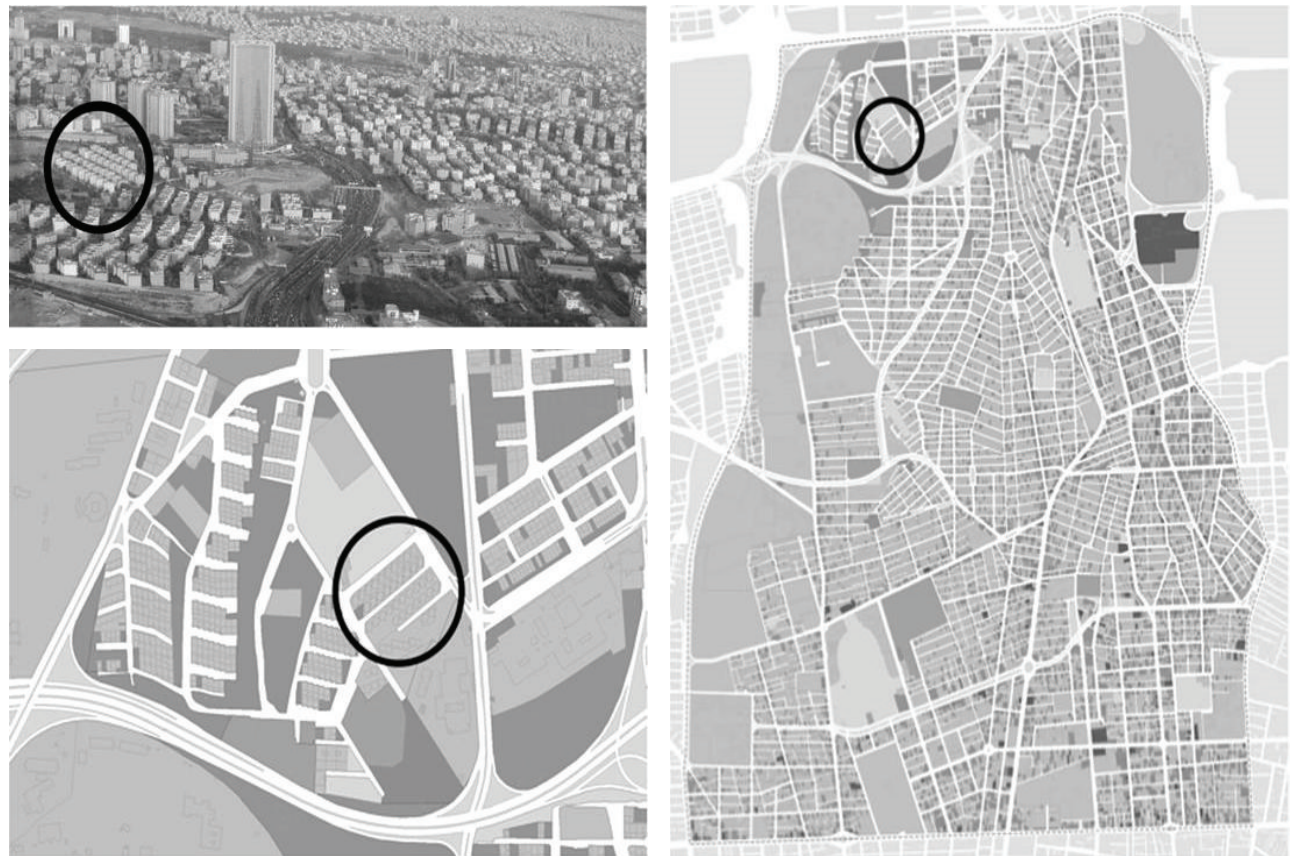

Figure 9: The location of study area in Tehran 6th urban district.

that roof greening was ineffective for human thermal comfort near the ground, due to the high building-height-to-streetwidth (H/W). They also found out that the amount of tree planting needed to lower pedestrian-level air temperature by around $1^{\circ} \mathrm{C}$ was approximately 33 per cent of the urban area. Another study investigated the effect of xeriscaping on near-surface temperatures and outdoor thermal comfort for two different areas in Phoenix [63]. Xerophytic trees have strong UHI mitigation potential in existing xeric residential areas in Phoenix, with greater cooling at microscales $\left(2.5^{\circ} \mathrm{C}\right)$ versus local scales $\left(1.1^{\circ} \mathrm{C}\right)$ and during nocturnal (05:00) versus daytime periods (17:00). Yang et al. [64] evaluated ENVImet with field data in terms of the thermal behavior of different types of ground surface. The results show that the model is capable of reasonably modeling the diurnal thermal behavior of different ground surfaces and their effect on air temperature and humidity. The simulated air temperature and humidity were generally consistent with the observations.

\section{UHI Mitigation Strategies and Results}

A densely built-up area in "urban district 6" with higher UHI intensity, as shown in Figure 6, was selected for simulation (Figure 9). The model area has a size of $230 \mathrm{~m} \times 234 \mathrm{~m}$, resulting in $94 \times 92 \times 25$ cells with a resolution of $2 \mathrm{~m}$. The selected area has a dense residential building morphology, quite common in Tehran, with an average height of $25 \mathrm{~m}$. The geographic co-ordinates of the model area were set to $35.73^{\circ}$ latitude and $51.50^{\circ}$ longitude.

ENVI-met simulations also require a configuration file containing local soil, meteorological, and building input data for model initialization in the study area. These include $2 \mathrm{~m}$ temperature and relative humidity, $10 \mathrm{~m}$ wind direction and speed, specific humidity at $2500 \mathrm{~m}$, soil temperature and relative humidity, building interior temperatures, thermal conductivity divided by mean wall or roof-width mean, heat transmission, and mean albedo for walls and roofs. These data were obtained from the measured data at Geophysics station (GEO), which is located near the study area and from the mobile measurements, respectively. Based upon the preliminary analyses of temperature, wind, and relative humidity obtained from GEO, a clear hot day (18 July 2009) was selected for the simulation. On this day, the measured data from GEO showed a maximum temperature of $38.4^{\circ} \mathrm{C}$ and a minimum of $29.2^{\circ} \mathrm{C}$, the mean $2 \mathrm{~m}$ temperature was $33.8^{\circ} \mathrm{C}$ with clear sky, presenting 12 hours of sunshine. The measured wind data confirmed the calm wind $(1.6 \mathrm{~m} / \mathrm{s})$ from West. The relative humidity was 35 percent, which is typical for a semiarid urban area such as Tehran in summer. The building information was obtained from typical thermophysical properties of typical building materials in this part of the 6 th district.

In order to study the UHI, the simulations of $15: 00 \mathrm{~h}$ (approximate maximum temperature timing) and 03:00 h (approximate minimum temperature timing) local time were selected for the analysis. The model was simulated for $48 \mathrm{~h}$ starting at 6 am on July 17th and ending at 3 am on July 19th. This is because the best time to start is at sunrise and the total runtime should be longer than 6 hours in order to overcome the influence of the initialization and allow the model to spin up. The weather parameters on July 17 th were very similar to 18 July 2009 . The main difference is $0.5 \mathrm{~K}$ higher minimum temperature and $0.2 \mathrm{~K}$ higher maximum temperature. 

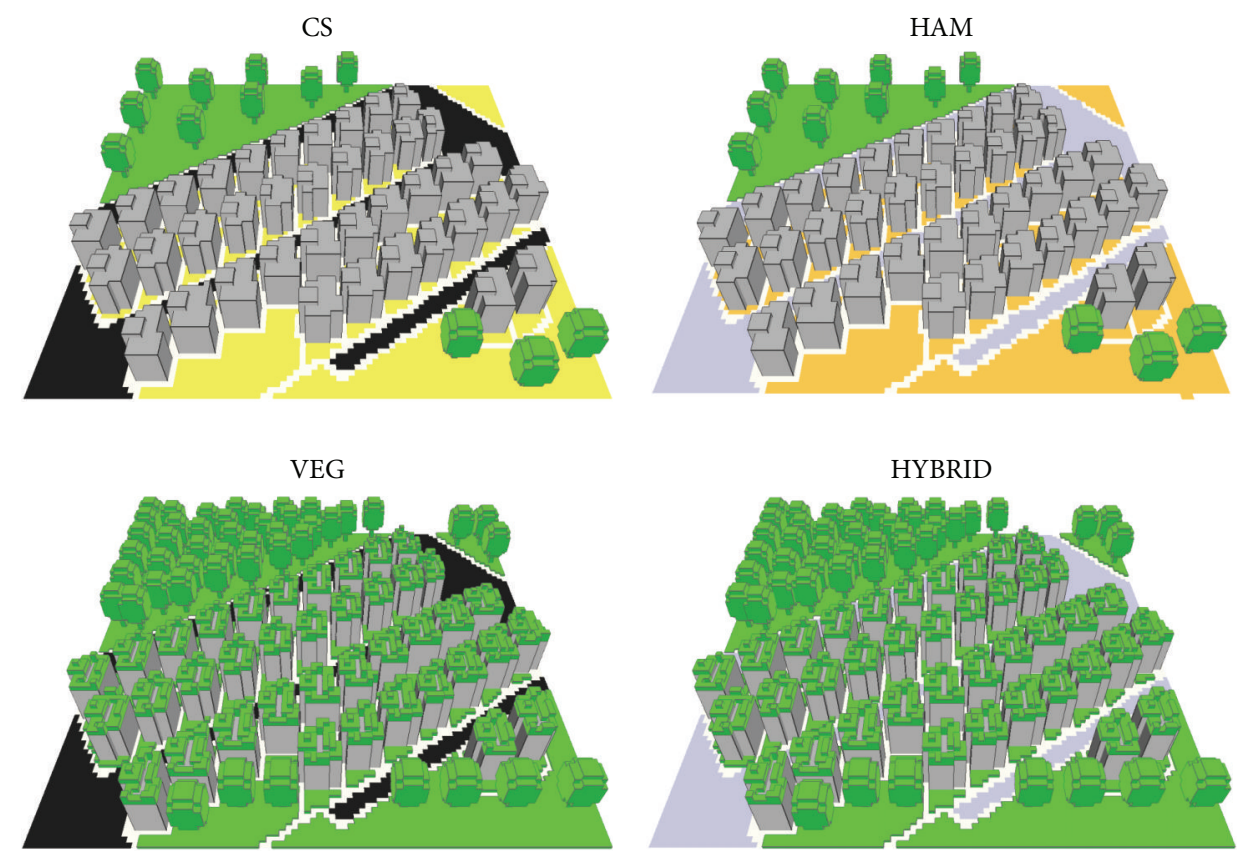

FIGURE 10: The current situation of the study area (CS) as well as with consideration of three mentioned UHI mitigation strategies; HAM: high albedo materials; VEG: greenery; HYBRID: HAM+VEG.

The ENVI-met model was run for the simulation of the current situation (CS) of "urban district 6" of Tehran as well as for three UHI mitigation scenarios.

Using ENVI-met, 3 different UHI mitigation strategies were applied and their cooling effects and feasibility are discussed as follows.

(i) Scenario 1: change current low albedo materials to high albedo materials (HAM).

(ii) Scenario 2: cover the model area with greenery (vegetation and green roofs, VEG).

(iii) Scenario 3: cover the model area with greenery along with high albedo materials (HYBRID).

Figure 10 shows the current situation of the investigated area (CS) as well as consideration of the three abovementioned UHI mitigation strategies. Greenery and vegetation reduced solar radiation and lowered near-surface air temperature due to evapotranspiration and shading and led to better thermal comfort conditions. Due to the already mentioned facts that greenery is the most widely applied mitigation measure, which could achieve huge energy-saving through temperature reduction in urban areas $[65,66]$, it has been applied in this study. Changing the albedo of roofs, façades, and pavements is the other applied mitigation method in this study, which is more feasible due to the water shortage in some summers in Tehran. The last scenario (Hybrid) combines the effect of high albedo materials and greenery (green roofs and more vegetation).

The current material used in buildings in the investigated area is concrete with an albedo of 0.30 . the material of roofs and roads are asphalt with an albedo of $0.14-0.16$, and some parts of the study area are covered by soil with an albedo of $0.17-0.23$. There is a lack of vegetation cover in this area (part of vegetation of whole model area: 18.15\%). In the first scenario, low albedo materials were changed to high albedo ones, asphalt to bright asphalt with albedo of 0.55 , concrete was covered with white coating with albedo of 0.85 , and soil was changed to light coloured soil with an albedo of 0.6. Using high albedo materials reduces the amount of incoming solar radiation absorbed through building envelopes and urban structures and thus keeps their surfaces cooler. The first scenario was selected because of the high value of sunshine duration in Tehran. In the second scenario, $43.44 \%$ of the simulated area is covered by vegetation (grass and shade trees with middle density canopies with a Leaf Area Index (LAI) of 2). Aroung each building is covered by shrubs (Buxus hyrcana hedges). Due to the fact that the cooling effect depends on the size of the vegetated area, each free cell in the study area has been covered by vegetation (grass) in order to obtain the maximum potential cooling effect. The vegetation on the roofs is considered as grass and shrubs. The simulation is only for summer, therefore no perennial plant has been considered for the simulation.

In the third scenario (HYBRID), the first two UHI mitigation scenarios were combined.

Figure 11, shows the $2 \mathrm{~m}$ potential temperature distribution in the study area in the current situation (CS) on a hot summer day (July 18) at 15:00 and at $03: 00 \mathrm{~h} \mathrm{local}$ time, respectively. As has been shown, maximum temperature in the current situation (circa $39^{\circ} \mathrm{C}$ ) occurs in roads with low albedo materials (asphalt) and the areas with less greenery located in the west and southwest of the area at 15:00 h. The simulation results show that, in green areas 
CS

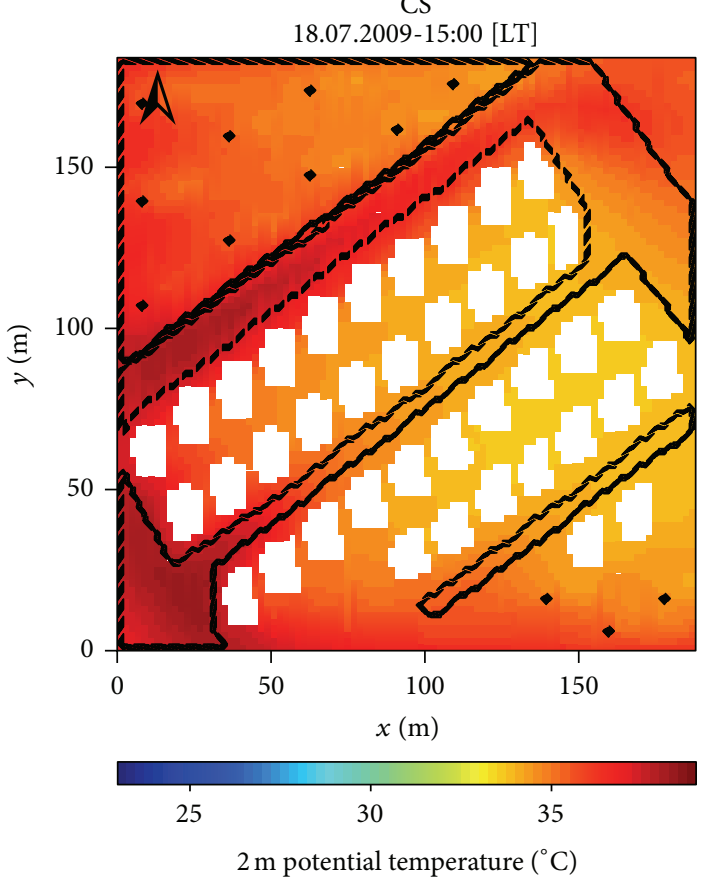

CS 19.07.2009-03:00 [LT]

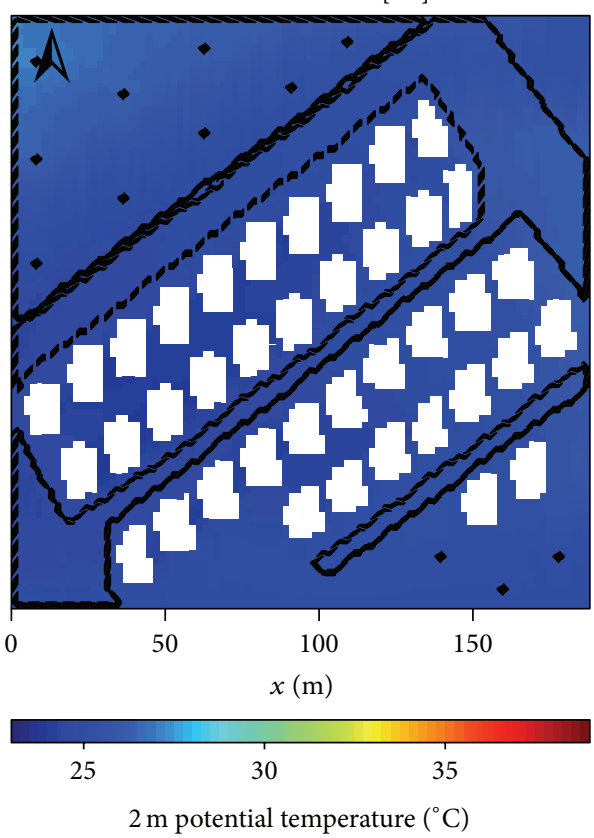

FIGURE 11: $2 \mathrm{~m}$ potential temperature distribution in the study area in current situation (CS) on a hot summer day (July 18th) at 15:00 and 03:00 h local time.

(the points represent the trees), lower temperatures (circa $34^{\circ} \mathrm{C}$ ) were observed. The residential area also shows a lower temperature due to shading and the higher albedo of the pavement. The maximum temperature decreased from $39^{\circ} \mathrm{C}$ at $15: 00 \mathrm{~h}$ to $27.5^{\circ} \mathrm{C}$ at $03: 00 \mathrm{~h}$ and occurred in the eastern part of the site in the current situation at $03: 00 \mathrm{~h}$ due to the wind advection from the west. It shows that advection and near-surface turbulence can influence the spatial distribution of $2 \mathrm{~m}$ temperature in this area and so the microscale warming or cooling effect can be expanded and reaches the surrounding area.

Figure 12 shows the $2 \mathrm{~m}$ potential temperature difference between CS and each UHI mitigation scenario at 15:00 and 03:00 h, respectively. In the first scenario (HAM), the cooling effect of high albedo materials can be seen especially in the built-up area and over the roads at 15:00 h. In comparison with the current situation, the temperature was decreased between 0.3 and $0.8 \mathrm{~K}$ in the built-up area due to reflected incoming solar radiation. The temperature reduction is higher over roads, which had an albedo increase of about 0.4 (asphalt to bright asphalt) and, in the current situation, showed the maximum temperature. In addition, maximum and minimum temperatures decreased by 0.7 and $1.42 \mathrm{~K}$, respectively.

At 03:00 h, built-up areas started to cool slowly, and, in comparison with the current situation, the temperature decreased by 0.3 and $0.6 \mathrm{~K}$. In addition, the middle part of the site (the residential area) was cooler than other parts when compared to current situation. It is clearly due to higher albedo change in this part (circa 0.55).
When greeneries (green roofs/more vegetated areas with middle density canopy trees) were added in the second scenario (Figure 11, VEG-CS), the temperature of urban areas was reduced by about $2-3 \mathrm{~K}$ in daytime $(15: 00 \mathrm{~h})$. While the greenery decreased the temperature due to shading (in case of trees) and evapotranspiration (in the case of all vegetation types), there was still higher temperature on the roads. Green roofs and Buxus hyrcana hedges contributed to decrease the temperature in the housing areas (local effect) by about $2.8 \mathrm{~K}$ at 15:00 h, which is similar to the cooling effect of middle density canopy trees in the northeastern part of study area in the daytime. The reduction of the air temperature in the area by more vegetation cover is smaller at night-time compared to daytime. Although the trees in consideration have a middle density canopy with a LAI of 2, they reduce the long wave radiation loss due to the smaller sky view factor and are responsible for a lower rate of cooling in the night-time. The temperature reduction in the housing area can reach $3.70 \mathrm{~K}$ at night-time, which is in agreement/line with the other studies $[25,26]$. In this scenario, all free spaces including roofs are covered by vegetation in order to estimate the maximum cooling effect of vegetation for a typical hot summer day in a semiarid climate.

In the third scenario (HYBRID), the combination of greenery and high albedo material was examined in order to test how these two strategies together can affect the near surface potential temperature (Figure 11, HYBRID-CS). The temperature was reduced up to $4.2 \mathrm{~K}$ in this case. The results show that HYBRID strategy leads to an overall cooling in the whole study area at 15:00 h, while the cooling is focused 
HAM-CS

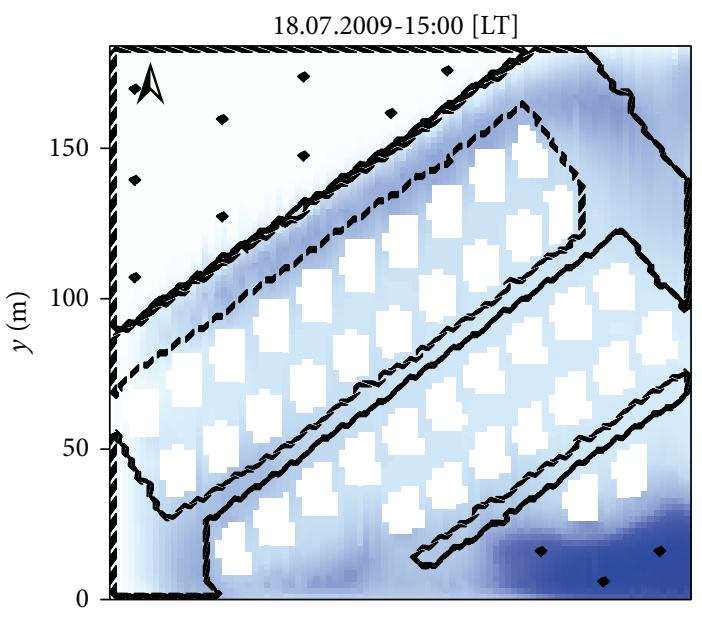

VEG-CS

18.07.2009-15:00 [LT]

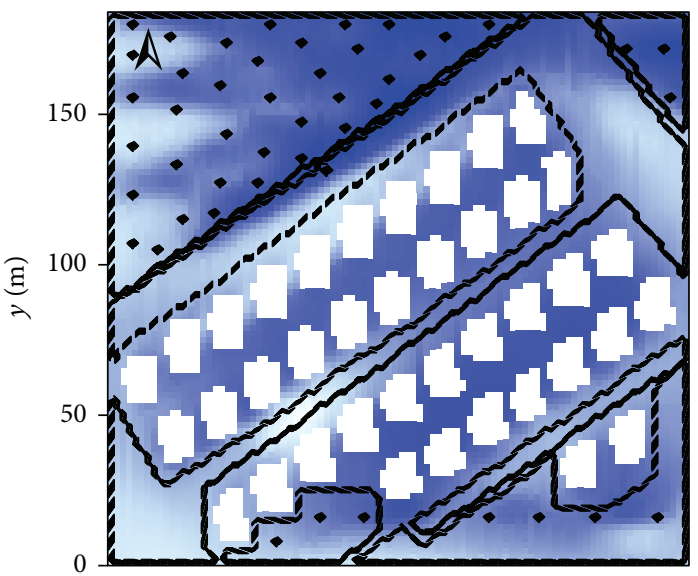

HYBRID-CS

18.07.2009-15:00 [LT]

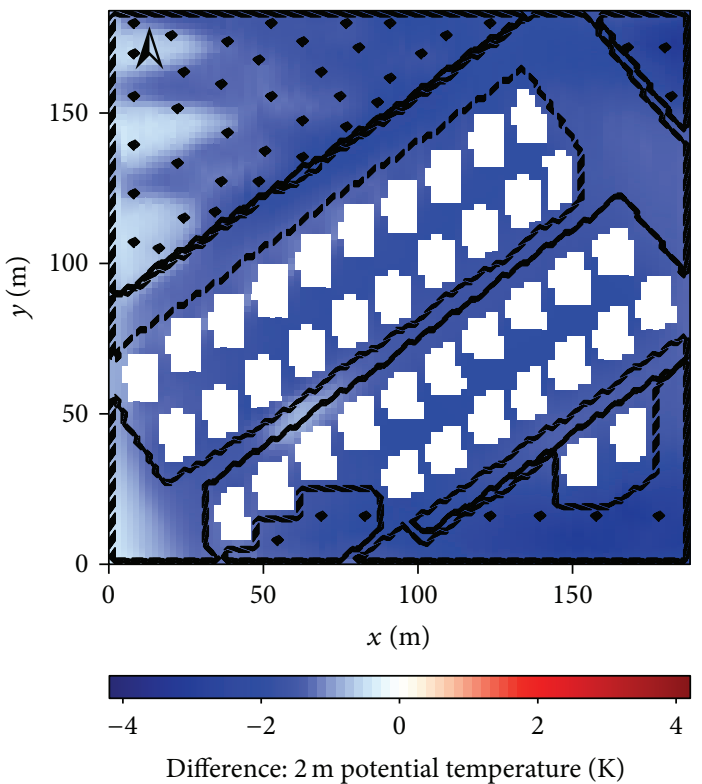

HAM-CS

19.07.2009-03:00 [LT]

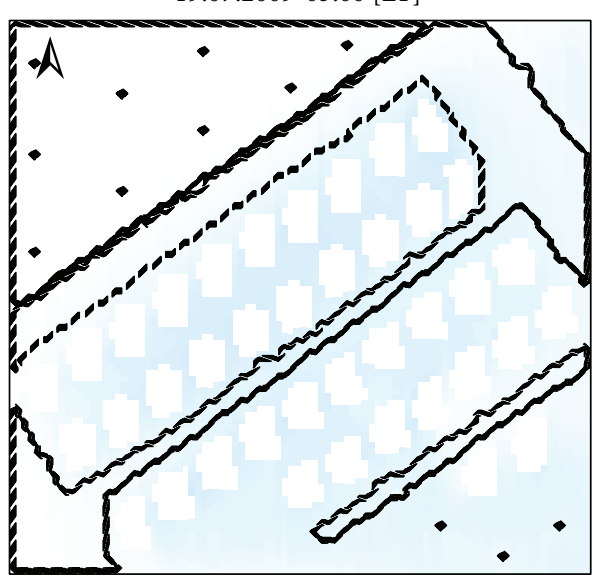

VEG-CS

19.07.2009-03:00 [LT]

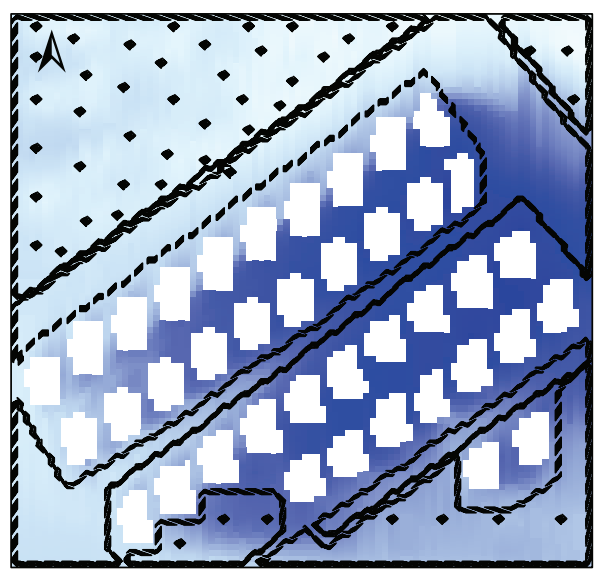

HYBRID-CS

19.07.2009-03:00 [LT]

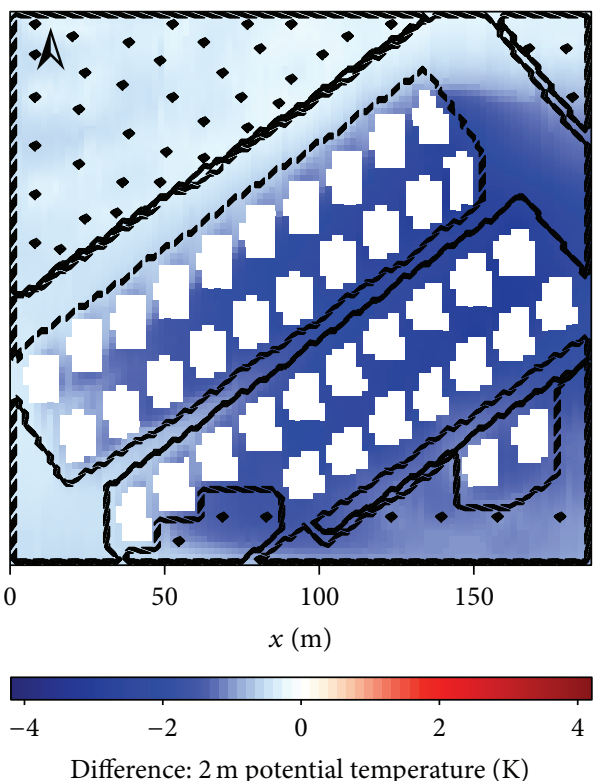

FIGURE 12: Potential temperature difference between CS and each UHI mitigation scenario at 15:00 and 03:00 h local time. 


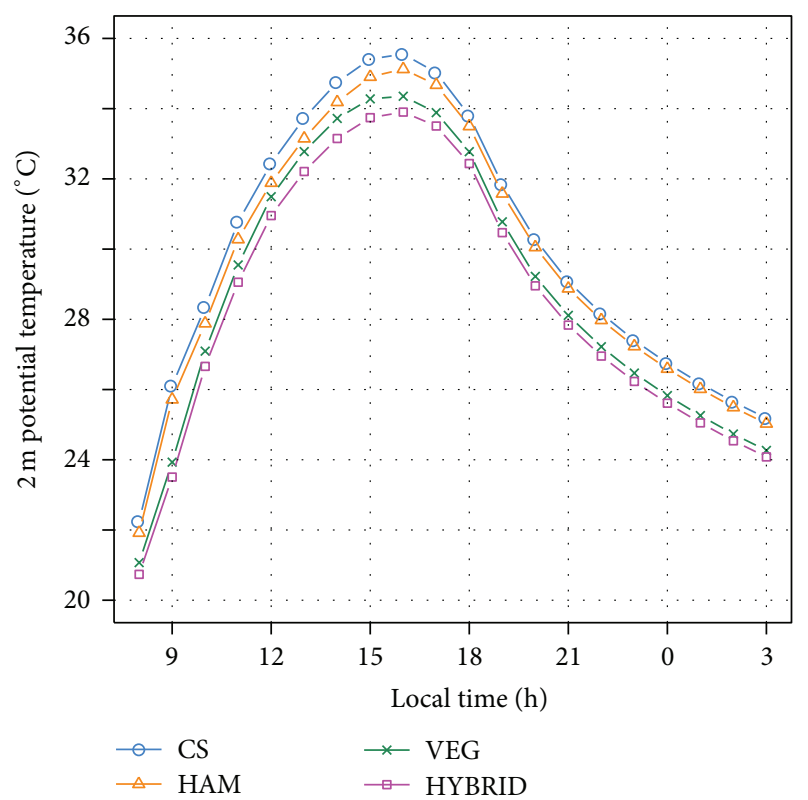

FIGURE 13: $2 \mathrm{~m}$ potential temperature time series simulated by ENVI-met from 08:00 July 18th 2009 till 03:00 19th 2009 for the current situation, as well as under consideration of three mentioned UHI mitigation strategies.

in the middle part at 03:00 h. Figure 11 shows that the park cool island intensity is higher in the daytime than in the night-time. It is due to the radiation trapped in the northern park, where middle density canopy trees are packed and lead to a reduction of long-wave radiation loss during the night. The first and second scenarios also contribute to reduce the temperature singly, while the third scenario makes a strong contribution to reduce the ambient temperature.

Figure 13 shows the $2 \mathrm{~m}$ potential temperature time series simulated by ENVI-met from 08:00 July 182009 till 03:00 192009 for the current situation, as well as taking the three above-mentioned UHI mitigation strategies into consideration. In this figure, the mean value over the whole simulated area is plotted. The results show that the mean temperature in the current situation is under-estimated by ENVI-met. As has been mentioned, the minimum and maximum temperatures of the Geophysics station, which is near the study area, were recorded at $29.4^{\circ} \mathrm{C}$ and $38.4^{\circ} \mathrm{C}$, although Figure 12 shows a maximum of $24^{\circ} \mathrm{C}$ and a minimum of $35.5^{\circ} \mathrm{C}$ in the current situation. The cooling effect of scenario HAM is effective only from 12:00 to $15: 00 \mathrm{~h}$ (about $0.5 \mathrm{~K}$ ); after 15:00 $\mathrm{h}$ there was no effective cooling. The VEG scenario shows a cooling of about $1^{\circ} \mathrm{C}$ on average, which decreases in the night-time. The HYBRID scenario had the same shape as the last two scenarios, but it leads to greater cooling (on average $1.5 \mathrm{~K}$ ) with a maximum in the daytime. As the Figure 12 demonstrates, the last two scenarios can bring about nocturnal cooling and can mitigate the UHI effect.

In order to understand the local effect of trees and bushes, as well as higher albedo buildings and pavements, three different points in the study area have been selected and their temperature time series plotted. Figure 14 shows the location

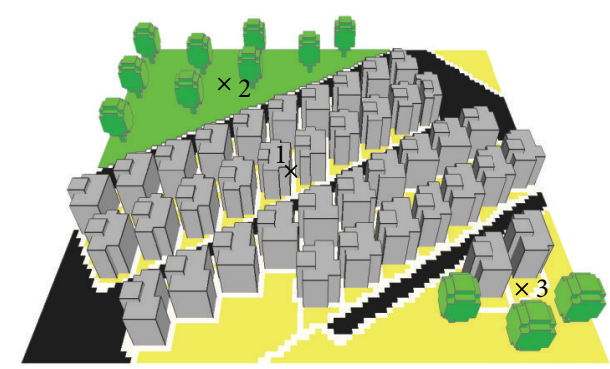

Figure 14: The location of three different points in the study area.

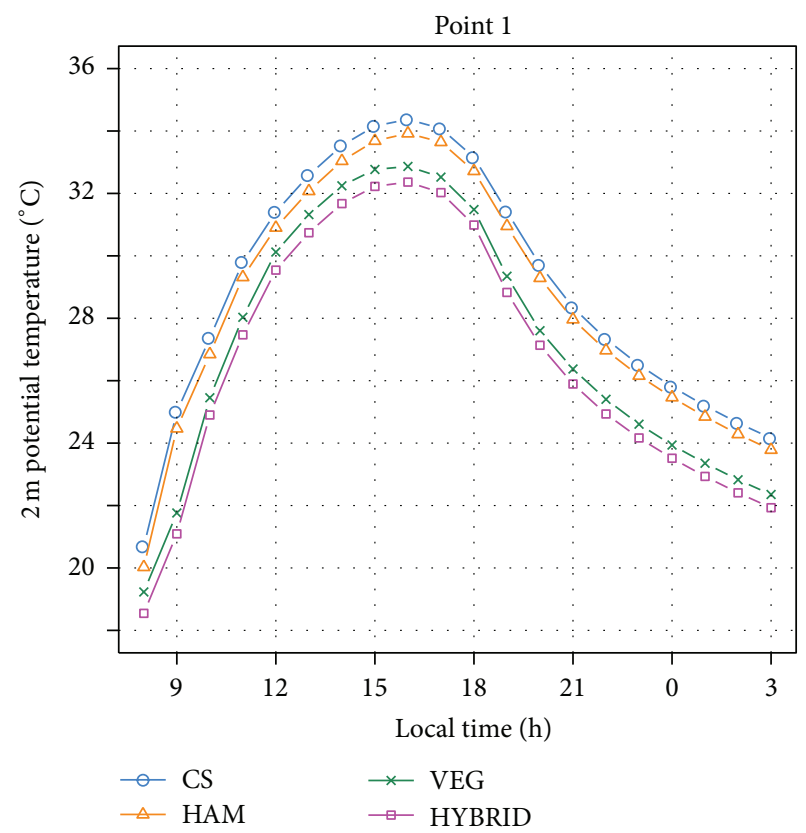

Figure 15: $2 \mathrm{~m}$ potential temperature time series at Point 1.

of these three points in the study area. The first point is located on the sidewalk between two buildings in the residential area. Point 2 is located in the northern park, and Point 3 is located in a low-density build-up area, surrounded by some trees.

Figure 15 shows the $2 \mathrm{~m}$ potential temperature time series of Point 1 . Although the point is located in the densely builtup area, changing the albedo has little cooling effect, with a minimum at night-time. The VEG and HYBRID scenarios have a much greater cooling effect, especially after 20:00 h. The maximum cooling is at $03: 00 \mathrm{~h}$ with a value more than $2 \mathrm{~K}$ with the HYBRID scenario. The temperature time series of Point 2 is shown in Figure 16. The HAM scenario shows no influence on the $2 \mathrm{~m}$ potential temperature. A significant similarity can be seen between the temperature time series under the VEG and HYBRID scenarios. They both show a maximum cooling of $1.8 \mathrm{~K}$ between 15:00-17:00, then cooling strongly decreases and shows a value of $0.3 \mathrm{~K}$ at $03: 00 \mathrm{~h}$, what is due to the dense trees in the northern park, which trap the heat due to the smaller sky view factor.

Figure 17 shows the temperature time series of Point 3. It is quite similar to the time series of Point 1 . The single 


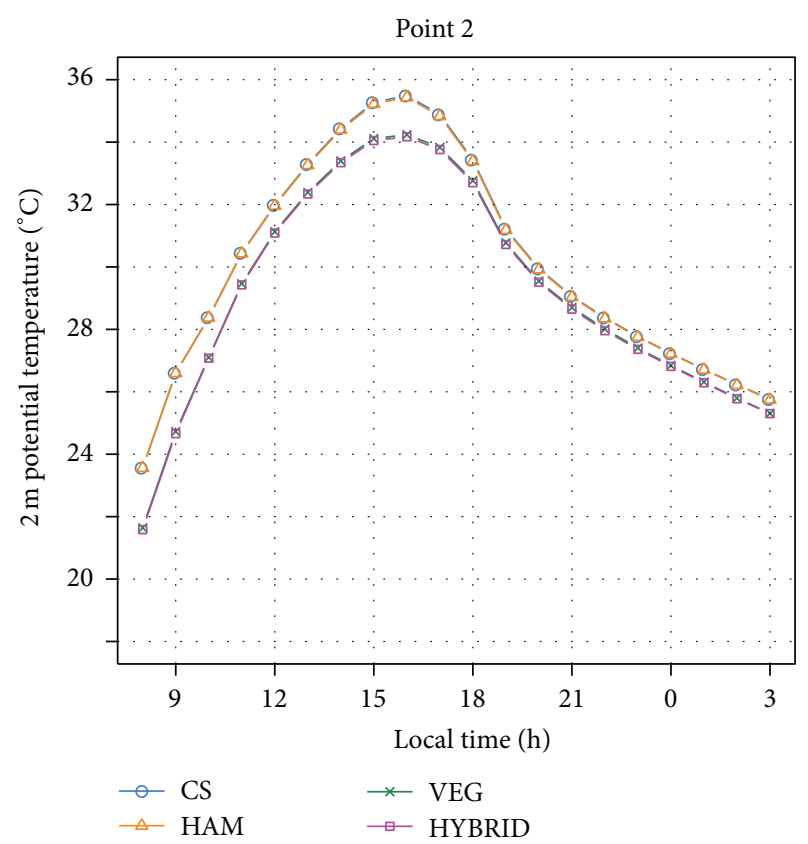

Figure 16: $2 \mathrm{~m}$ potential temperature time series at Point 2.

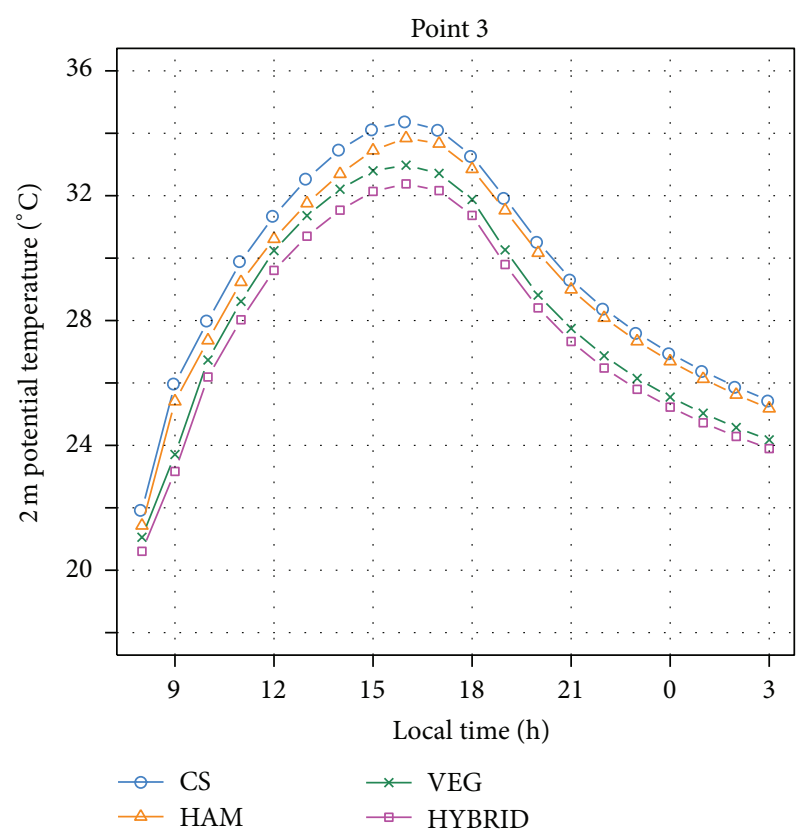

FIgURE 17: $2 \mathrm{~m}$ potential temperature time series at Point 3.

difference is the smaller nocturnal cooling under VEG and HYBRID scenarios at Point 3 , which shows the positive effect of greenery in the residential area, where Point 1 is located.

As Figure 18 shows, relative humidity of 35.27 percent was observed in the built-up area of the current situation in daytime, while it increased by between 3 and 5 percent in the last two scenarios (shown only for VEG). Evapotranspiration in the northern park brings about an increase in the dew point temperature and raises the relative humidity. It also increased between 7 and 9 percent when the last two scenarios are taken into consideration in comparison with the current situation at night-time (not shown). This increase in relative humidity leads to better human comfort conditions (optimal level $40 \%-60 \%)$. The vegetation reduced wind speed in the second and third scenarios is due to the tree density in the northern part. In the cross-comparison of the three scenarios for wind speed, the wind speed became high in the first scenario with no vegetation. Higher wind speed zones appear in the street canyon due to the channel effect from the two sides of the blocks.

The ENVI-met simulation supported the data generated from field measurement. It indicates that greenery along with high albedo material has a significant cooling effect of up to $4.2 \mathrm{~K}$ on the surroundings during both, day- and nighttime, which can save a huge amount of energy, which is normally used for air conditioning. In addition, ENVI-met simulation shows that the lack of greenery and materials with high albedo may cause bad thermal condition (higher temperature and lower relative humidity) especially in urban areas with hard and low albedo surfaces. Wind strength and direction can affect the size of the cooled area around a green space, which has to be investigated in further studies using mesoscale models. Due to the limitation of ENVI-met, it was not possible to simulate the whole of Tehran.

\section{Discussion and Conclusion}

This study has investigated the UHI characteristic in megacity Tehran and suggested some mitigation strategies regarding their feasibility. Population growth, the increase in the number of cars, energy consumption, and the resulting heat from new built-up areas have all caused stronger UHI and a high concentration of air pollutants in Tehran. The largest UHI intensity was recorded in summer (July) with a mean value of $6.1 \mathrm{~K}$ over 19 years (1991-2009) and the smallest one was recorded in winter, with an average minimum value in December about $2.17 \mathrm{~K}$. A Landsat 7 ETM+ satellite image from a hot summer day was employed to map the surface temperature in Tehran, to identify hot spots. For the study, a high density built-up district with low albedo materials was selected (Urban District 6). Mobile temperature measurement in this area in 2 time sessions $(13: 00-15: 00 \mathrm{~h}$ and 21:00-23:00 h) on a typical hot day (18 July 2009) was carried out. A maximum daily temperature of $42.6^{\circ} \mathrm{C}$ was observed at industrial land use located in Enghelab Street and the lowest one $\left(30.1^{\circ} \mathrm{C}\right)$ was observed in the Saai and Laleh parks, which shows the local effect of low albedo materials and greenery on the temperature. The mobile measurement shows higher temperatures compared to the permanent station GEO in this district. The results of the field survey shows clear evidence of higher temperatures in the middle part when compared to the green areas in 6th/urban district of Tehran, with the high density residential, commercial, and industrial land use areas showing a higher temperature of circa 6-7 K.

In the last part, three different UHI mitigation strategies (high albedo materials, green roofs and vegetation, and hybrid) were simulated for a high density built-up area in the 


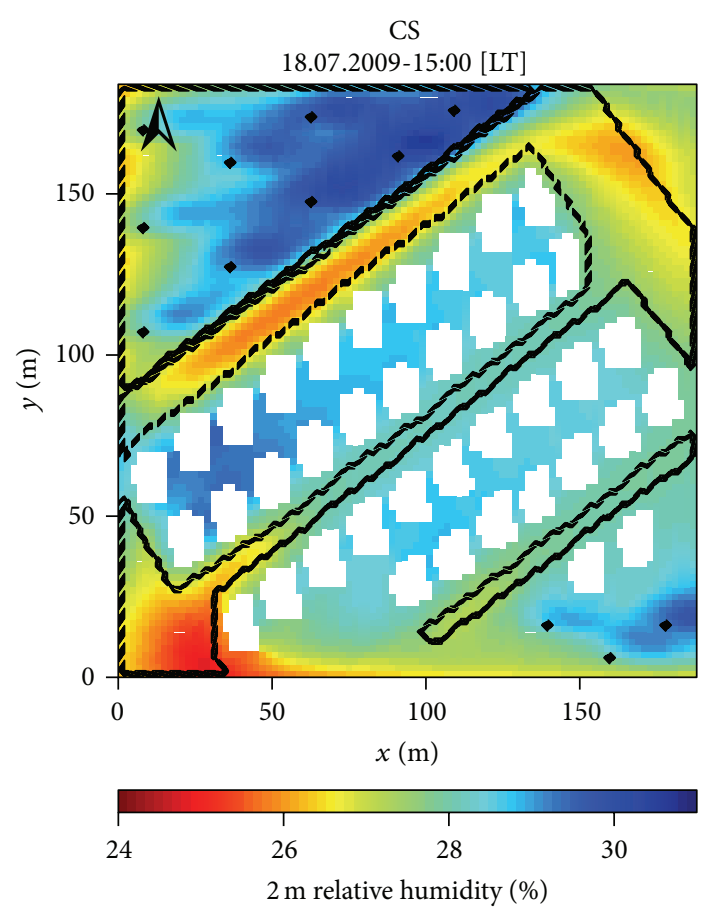

(a)

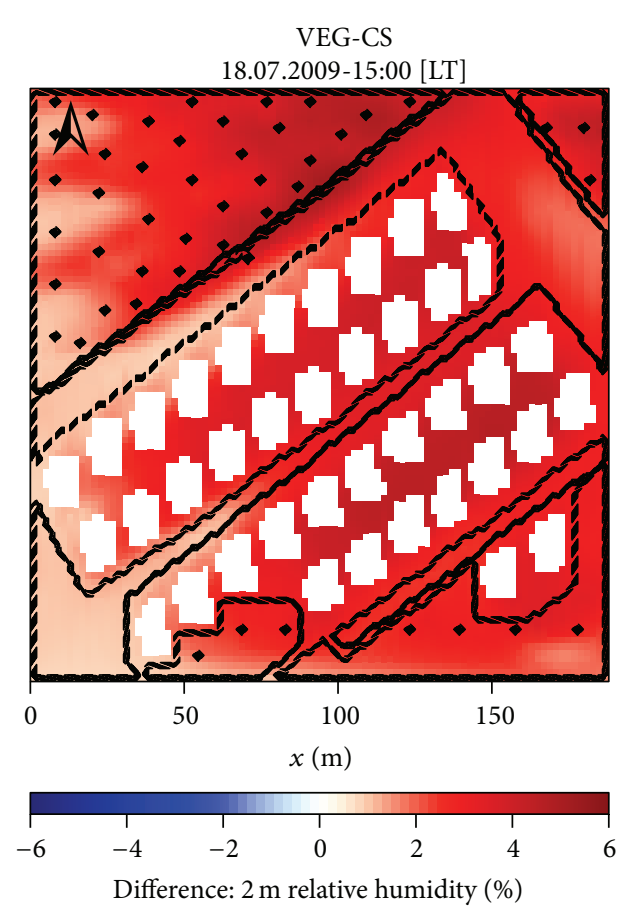

(b)

FIGURE 18: 2m relative humidity on July 18th 2009 (a) in current situation and (b) its difference from the case under VEG scenario.

6th urban district of Tehran. The key result from this study is the estimation of the cooling potential of these strategies as UHI mitigation methods, especially in residential areas in the megacity of Tehran on a hot summer day (18 July 18 2009). The results from the ENVI-met simulations presented in this study clearly show that using high albedo materials (HAM) leads to a cooling of $0.5 \mathrm{~K}$ in daytime $(15: 00 \mathrm{~h})$, although it is much lower $(0.16 \mathrm{~K})$ in the night-time $(03: 00 \mathrm{~h})$. So it brings only slight cooling in residential area during the night and cannot be considered as an effective mitigation strategy, although, due to the high number of hours of sunshine per day in Tehran, reduction in the heat storage of sunlit surfaces seems to be important. White roof coatings could also be applied over asphalt shingles. When first applied, these can provide an albedo up to 0.8 , which means that only 20 per cent of the sun's energy is being absorbed as heat, which leads to higher cooling compared to our results. However they do become dirty due to critical air pollution in Tehran and after, a short time, their reflectance may be reduced to about 0.5 .

In the second scenario (VEG), all free spaces within the study-including roofs-are covered by vegetation (grass, Buxus hyrcana, and trees with middle density canopy), in order to obtain maximal cooling, which is generated only by vegetation. The results show that the average cooling for the whole area is about $1.13 \mathrm{~K}$ at $15: 00$ and $0.92 \mathrm{~K}$ at 03:00 h. The nocturnal temperature decreased by about $2 \mathrm{~K}$ in the residential area, which is much greater than the slight cooling in the northern park. The results of this scenario confirmed the results of $\mathrm{Ng}$. [41], which demonstrated that green areas should constitute at least 33 per cent of the urban area to lower the temperature by about $1^{\circ} \mathrm{C}$. In our case, the greenery covers about 43 percent of the whole area.

The third scenario combines the last two scenarios (HYBRID) and shows the greatest cooling. The average cooling of this scenario is about $1.67 \mathrm{~K}$ at $15: 00 \mathrm{~h}$ and $1.10 \mathrm{~K}$ at 03:00 $\mathrm{h}$, although the maximum cooling is about $4.2 \mathrm{~K}$ in the green area between the buildings in daytime and night-time, respectively.

This paper demonstrates the influence of greenery compared to high albedo materials in order to mitigate the urban heat island intensity in megacity Tehran. As is shown, the last two scenarios give promising insights into the benefits of urban green planning. Developing green spaces reduces the air pollution and filters the particulate matter, on the one hand, and reduces the near-surface air temperature and prevents the overheating of sunlit surfaces, on the other. Although the effect of $25 \mathrm{~m}$ green roofs on the $2 \mathrm{~m}$ temperature is smaller than the effect of surface greenery, their air pollution filtering potentials are the same. If regular irrigation is applied, then evapotranspiration should also be taken into account, although, due to the lack of water in the soil in hot summer, the evapotranspiration rate is low in Tehran. Trees also present some disadvantages. They reduce the wind speed and lead to trap heat and humidity inside the urban canopy layer, which causes warmer nocturnal temperatures as well as cooler daily temperatures, when compared to free spaces without vegetation, as has been shown for the Point 2 , which is located in the northern park.

Tehran is a part of a semiarid region in the world and has encountered acute crises due both to the increase in the population and the corresponding increase in the need 
of water resources. The per capita water consumption rate for Tehran was more than 300 litres per day in 2007, which is twice the international and even national level [67]. This shortage is due to the low annual precipitation (ca. $230 \mathrm{~mm}$, [34]) as well as low available water resources. Due to this lack of water, especially during summers in Tehran, the feasibility of the mentioned UHI mitigation strategies (e.g., the irrigation of green roofs by treated waste water) should be considered and discussed by stakeholders.

Akbari found that peak energy demand in the USA rises circa 2-4 per cent for every $1 \mathrm{~K}$ increase in maximum air temperature [68]. This means that if we are able to reduce the maximum temperature by about 2-3K (by cooling residential areas with the VEG and HYBRID scenarios), then we can reduce energy consumption by about 5-10 per cent, which would be a huge saving in energy and would also lead to better conditions of human comfort and serve to offset global warming.

It should be further noted that, due to the limitation of ENVI-met, it is not possible to make the simulation for the whole city in order to investigate the size of the area which would be affected by the increased cooling, although the mesoscale models are able to simulate it, but, due to lower resolution, are not able to show the localised or microscale impact of the vegetation, for example, the effect of bushes or trees near buildings. Coupling meso- microscale model could be useful to investigate the potential cooling effect of different strategies on different scales of climate change under consideration.

\section{Conflict of Interests}

The authors declare that there is no conflict of interests regarding the publication of this paper.

\section{Acknowledgments}

The financial support of the Ministry of Education and Research in Germany as well as German Academic Exchange Service (DAAD) within the frame of the project "Young Cities-Developing Energy-Efficient Urban Fabric in the Tehran-Karaj Region" is gratefully acknowledged. Authors also acknowledge IR of Iran Meteorological Organization for providing the data. Authors are grateful to Dr. Ahmadnezhad from the department of Epidemiology and Biostatistics of Tehran University for providing the mortality data.

\section{References}

[1] A. Madanipour, "Urban planning and development in Tehran," Cities, vol. 23, no. 6, pp. 433-438, 2006.

[2] Z. Fanni, "Cities and urbanization in Iran after the Islamic revolution," Cities, vol. 23, no. 6, pp. 407-411, 2006.

[3] A. Madanipour, Tehran: The Making of a Metropolis, John Wiley \& Sons, London, UK, 1998.

[4] E. Ehlers and W. Floor, "Urban change in Iran, 1920-1941," Iranian Studies, vol. 26, no. 3-4, pp. 251-275, 1993.

[5] M. Semsar, Tehran Eine Stadtgeographische Studie, Springer, Vienna, Austria, 1986.
[6] N. Najmi, Iran-e Ghadim va Tehran-e Ghadim, Janzadeh, Tehran, Iran, 1984.

[7] A. Farmanfarmaian and V. Gruen, "Tarh-e Jame-e Tehran, Tehran," Sazman-e Barnameh va Budgeh, Tehran, Iran, 1968.

[8] M. R. Emmanuel, An Urban Approach to Climate-Sensitive Design; Strategies for the Tropics, Spon Press, London, UK, 2005.

[9] D. N. Asimakopoulos, V. D. Assimakopoulos, N. Chrisomallidou et al., Energy and Climate in the Urban Built Environment, James \& James Publication, London, UK, 2001.

[10] T. R. Oke, "Towards better scientific communication in urban climate," Theoretical and Applied Climatology, vol. 84, no. 1-3, pp. 179-190, 2006.

[11] B. Givoni, Climate Considerations in Building and Urban Design, John Wiley \& Sons, Toronto, Canada, 1998.

[12] T. R. Oke, "The energetic basis of the urban heat island," Quarterly Journal of the Royal Meteorological Society, vol. 108, no. 455, pp. 1-24, 1982.

[13] M. Darand and A. Halabian, "Classification synoptic circulation patterns impacting on air pollution in Tehran," Journal of Applied Sciences Research, vol. 3, no. 5, pp. 140-146, 2013.

[14] IPCC, Climate Change 2007: The Physical Science Basis. Contribution of Working Group I to the Fourth Assessment Report of the Intergovernmental Panel on Climate Change, Cambridge University Press, 2007.

[15] N. H. Wong and Y. Chen, Tropical Urban Heat Islands: Climate, Buildings and Greenery, Taylor \& Francis, London, UK, 2009.

[16] H. Akbari, L. S. Rose, and H. Taha, "Analyzing the land cover of an urban environment using high-resolution orthophotos," Landscape and Urban Planning, vol. 63, no. 1, pp. 1-14, 2003.

[17] A. Niachou, K. Papakonstantinou, M. Santamouris, A. Tsangrassoulis, and G. Mihalakakou, "Analysis of the green roof thermal properties and investigation of its energy performance," Energy and Buildings, vol. 33, no. 7, pp. 719-729, 2001.

[18] E. G. McPherson, D. J. Nowak, and R. A. Rowntree, "Chicago's urban forest ecosystem: results of the Chicago urban forest climate project," Tech. Rep. NE-186, Forest Service, U.S. Department of Agriculture, 1994.

[19] A. H. Rosenfeld, H. Akbari, J. J. Romm, and M. Pomerantz, "Cool communities: strategies for heat island mitigation and smog reduction," Energy and Buildings, vol. 28, no. 1, pp. 51-62, 1998.

[20] T. Asaeda, V. T. Ca, and A. Wake, "Heat storage of pavement and its effect on the lower atmosphere," Atmospheric Environment, vol. 30 , no. 3 , pp. $413-427,1996$.

[21] H. Taha, "Urban climates and heat islands: albedo, evapotranspiration, and anthropogenic heat," Energy and Buildings, vol. 25, no. 2, pp. 99-103, 1997.

[22] H. Akbari, S. Davis, S. Dosano, J. Huang, and S. Winnett, Cooling Our Communities: A Guidebook on Tree Planting and Light-Colored Surfacing, United States Environmental Protection Agency, Washington, DC, USA, 1992.

[23] T. R. Oke, G. T. Johnson, D. G. Steyn, and I. D. Watson, "Simulation of surface urban heat islands under "ideal" conditions at night part 2: diagnosis of causation," Boundary-Layer Meteorology, vol. 56, no. 4, pp. 339-358, 1991.

[24] E. I. Griggs, T. R. Sharp, and J. M. MacDonald, "Guide for estimating differences in building heating and cooling energy due to changes in solar reflectance of a low-sloped roof," Oak Ridge National Laboratory Report ORNL-6527, 1989.

[25] H. Tong, A. Walton, J. Sang, and J. C. L. Chan, "Numerical simulation of the urban boundary layer over the complex 
terrain of Hong Kong," Atmospheric Environment, vol. 39, no. 19, pp. 3549-3563, 2005.

[26] T. V. Ca, T. Asaeda, and E. M. Abu, "Reductions in air conditioning energy caused by a nearby park," Energy and Buildings, vol. 29, no. 1, pp. 83-92, 1998.

[27] Y. Kikegawa, Y. Genchi, H. Kondo, and K. Hanaki, "Impacts of city-block-scale counter measures against urban heat island phenomena upon a building's energy consumption for airconditioning," Applied Energy, vol. 83, no. 6, pp. 649-668, 2006.

[28] H. Taha, S. Konopacki, and S. Gabersek, "Impacts of large scale modifications on meteorological conditions and energy use: A 10-region modeling study," Theoretical and Applied Climatology, vol. 62, pp. 175-185, 1999.

[29] Y. Ashie, V. C. Thanh, and T. Asaeda, "Building canopy model for the analysis of urban climate," Journal of Wind Engineering and Industrial Aerodynamics, vol. 81, pp. 237-248, 1999.

[30] W. T. L. Cow and A. J. Brazel, "Assessing xeriscaping as a sustainable heat island mitigation approach for a desert city," Building and Environment, vol. 7, pp. 170-181, 2011.

[31] R. Priyadarsini, W. N. Hien, and C. K. W. David, "Microclimatic modeling oft he urban thermal environment of Singapore to mitigate urban heat island," Solar Energy, vol. 82, pp. 727-745, 2008.

[32] E. Ahmadnezhad, K. H. Naieni, A. Ardalan et al., "Excess mortality during heat waves, Tehran Iran: an ecological timeseries study," Journal of Research in Health Sciences, vol. 13, no. 1, pp. 24-31, 2013.

[33] M. Bruse and H. Fleer, "Simulating surface-plant-air interactions inside urban environments with a three dimensional numerical model," Environmental Modelling and Software, vol. 13, no. 3-4, pp. 373-384, 1998.

[34] P. Zawar-Reza, "Numerical analysis of the 120 day wind over the Sistan Region, South-West Asia with TAPM," Clean Air and Environmental Quality, vol. 41, pp. 21-24, 2008.

[35] W. Fisher, The Cambridge History of Iran, vol. 1 of Physical Geography, Cambridge University Press, Cambridge, UK, 1968.

[36] S. M. Habibi and B. Hourcade, Atlas of Tehran Metropolis, Pardazesh va Barnamerizi -e Shahri Publications, Tehran, Iran, 2005.

[37] T. R. Oke, Boundary Layer Climates, Routledge, London, UK, 2nd edition, 1987.

[38] P. Zawar-Reza, T. Appelhans, M. Gharaylou, and A. Shamsipour, "Mesoscale controls on particulate matter pollution for a mega city in a semi-arid mountainous environment: Tehran, Iran," International Journal of Environment and Pollution, vol. 41, no. 1-2, pp. 166-183, 2010.

[39] B. Alijani, "Temporal changes of Tehran temperature," in Proceedings of the Conference Proceedings of first regional on Climate Change, pp. 22-24, Tehran, Iran, 1997.

[40] M. Jahadi Toroghi, "Variation of temperature and precipitation of Mashhad during 1951-1994," Iranian Quarterly Geographical Research Journal, vol. 54, pp. 151-165, 2000 (Persian).

[41] A. Rasooli, "Analysis of time series of Tabriz air temperature," Iranian Nivar Journal, vol. 46, pp. 7-26, 2002 (Persian).

[42] F. Rahimzadeh and A. Asgari, "A survey on recent climate change over IRAN," in Proceedings of 14th Global Warming International Conference \& Expo, pp. 27-30, Boston, Mass, USA, 2003.

[43] F. Rahimzadeh and A. Asgari, "A look at difference of increase rates of minimum with maximum temperature and at decrease rates of Diurnal Temperature Range (DTR) in Iran," Iranian
Quarterly Geographical Research Journal, vol. 73, pp. 153-171, 2005 (Persian).

[44] M. Pedram, F. Rahimzadeh, F. Sahraian, and K. Noohi, "Change in the frost free season length and number of frost days in the west and east Azerbaijan provinces," in Proceedings of the 1st International Conference on Climate Change and the Middle East: Past, Present and Future, pp. 20-23, Istanbul Technical University, 2005.

[45] F. Rahimzadeh, A. Asgari, and E. Fattahi, "Variability of extreme temperature and precipitation in Iran during recent decades," International Journal of Climatology, vol. 29, no. 3, pp. 329-343, 2009.

[46] S. Marofi, M. M. Sohrabi, K. Mohammadi, A. A. Sabziparvar, and H. Z. Abyaneh, Investigation of Meteorological Extreme Events over Coastal Regions of Iran, Springer, 2010.

[47] F. Tagavi and H. Mohammadi, "Studying the return period of climatic extreme events in order to understand their environmental effects," Journal Environmental Studies, vol. 43, pp. 11-20, 2007.

[48] S. Alijani and B. Alijani, "Analysis of climate hazards in relation to urban designing in Iran," Advances in Sciences and Research, vol. 6, pp. 173-178, 2011.

[49] M. Vahedi, Tehran va masa'el-e zist mohiti. Seminar-e tadavom-e hayat dar baft-e shahrha-ye ghadimi-e, Elm va San'at University Press, Tehran, Iran, 1989.

[50] D. O. Åström, F. Bertil, and R. Joacim, "Heat wave impact on morbidity and mortality in the elderly population: a review of recent studies," Maturitas, vol. 69, no. 2, pp. 99-105, 2011.

[51] S. Lofti and M. J. Koohsari, "Measuring objective accessibility to neighborhood facilities in the city (a case study: zone 6 in Tehran, Iran)," Cities, vol. 26, no. 3, pp. 133-140, 2009.

[52] A. R. Saatabadi and A. A. Bidokhti, "Urbanization effects on local climate in Tehran Megapolis," Research Journal of Environmental Sciences, vol. 5, no. 1, pp. 1-21, 2011.

[53] P. Shahmohamadi, U. Cubasch, S. Sodoudi, and A. I. Che-Ani, Air Pollution, chapter 11, INTECH Press, 2012, edited by B. Haryanto.

[54] E. Ng, L. Chen, Y. Wang, and C. Yuan, "A study on the cooling effects of greening in a high-density city: an experience from Hong Kong," Building and Environment, vol. 47, no. 1, pp. 256271, 2012.

[55] C. Rosenzweig, W. D. Solecki, L. Parshall, M. Chopping, G. Pope, and R. Goldberg, "Characterizing the urban heat island in current and future climates in New Jersey," Global Environmental Change B, vol. 6, no. 1, pp. 51-62, 2005.

[56] I. D. Stewart, "A systematic review and scientific critique of methodology in modern urban heat island literature," International Journal of Climatology, vol. 31, no. 2, pp. 200-217, 2011.

[57] Y. Zhou and J. M. Shepherd, "Atlanta's urban heat island under extreme heat conditions and potential mitigation strategies," Natural Hazards, vol. 52, no. 3, pp. 639-668, 2010.

[58] Y. H. Kim and J. J. Baik, "Maximum urban heat island intensity in Seoul," Journal of Applied Meteorolgy, vol. 41, pp. 651-659, 2002.

[59] J. Unger, Z. Sümeghy, and J. Zoboki, “Temperature cross-section features in an urban area," Atmospheric Research, vol. 58, no. 2, pp. 117-127, 2001.

[60] Y. Liu, F. Chen, T. Warner, S. Swerdlin, J. Bowers, and S. Halvorson, "Improvements to surface flux computations in a nonlocal-mixing PBL scheme, and refinements on urban processes 
in the Noah land-surface model with the NCAR/ATEC realtime FDDA and forecast system," in Proceedings of the 20th Conference on Weather Analysis and Forecasting/16th Conference on Numerical Weather Prediction, Seattle, Wash, USA, January 2004.

[61] S. Sodoudi, A. Noorian, M. Geb, and E. Reimer, "Daily precipitation forecast of ECMWF verified over Iran," Theoretical and Applied Climatology, vol. 99, no. 1-2, pp. 39-51, 2010.

[62] G. R. Roshan, S. Z. Shahraki, D. Sauri, and R. Borna, "Urban sprawl and climatic changes in Tehran," Iranian Journal of Environmental Health Science and Engineering, vol. 7, no. 1, pp. 43-52, 2010.

[63] W. T. L. Chow and A. J. Brazel, "Assessing xeriscaping as a sustainable heat island mitigation approach for a desert city," Building and Environment, vol. 47, no. 1, pp. 170-181, 2012.

[64] X. Yang, L. Zhao, M. Bruse, and Q. Meng, "Evaluation of a microclimate model for predicting the thermal behavior of different ground surfaces," Building and Environment, vol. 60, pp. 93-104, 2013.

[65] Y. Kikegawa, Y. Genchi, H. Kondo, and K. Hanaki, "Impacts of city-block-scale countermeasures against urban heat-island phenomena upon a building's energy-consumption for airconditioning," Applied Energy, vol. 83, no. 6, pp. 649-668, 2006.

[66] Y. Ashie, V. T. Ca, and T. Asaeda, "Building canopy model for the analysis of urban climate," Journal of Wind Engineering \& Industrial Aerodynamics, vol. 81, pp. 237-248, 1999.

[67] H. R. Jahani, "Role of ground water in the Tehran water supply," in Groundwater Management Practices, A. N. Findikakis and K. Sato, Eds., pp. 111-122, CRC Press, New York, NY, USA, 2011.

[68] S. E. Asgharpour, H. Zanjani, and G. Taleghani, "Impact of urbanization on population changes in metropolitan area of Tehran, Iran," in Proceedings of the 3rd International Geography Symposium-GEOMED Symposium Proceedings, 2013. 

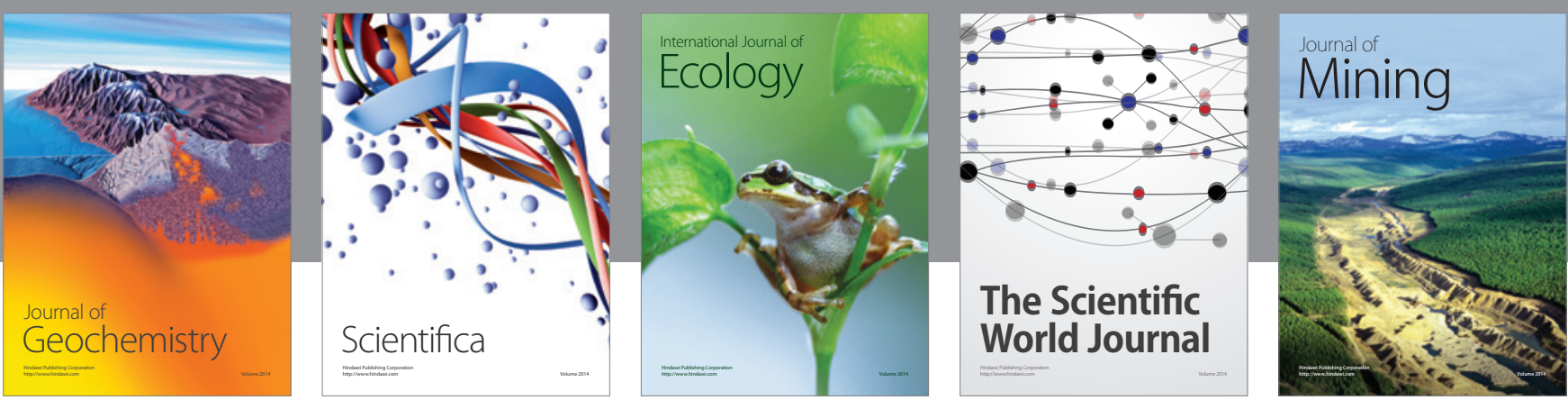

The Scientific World Journal
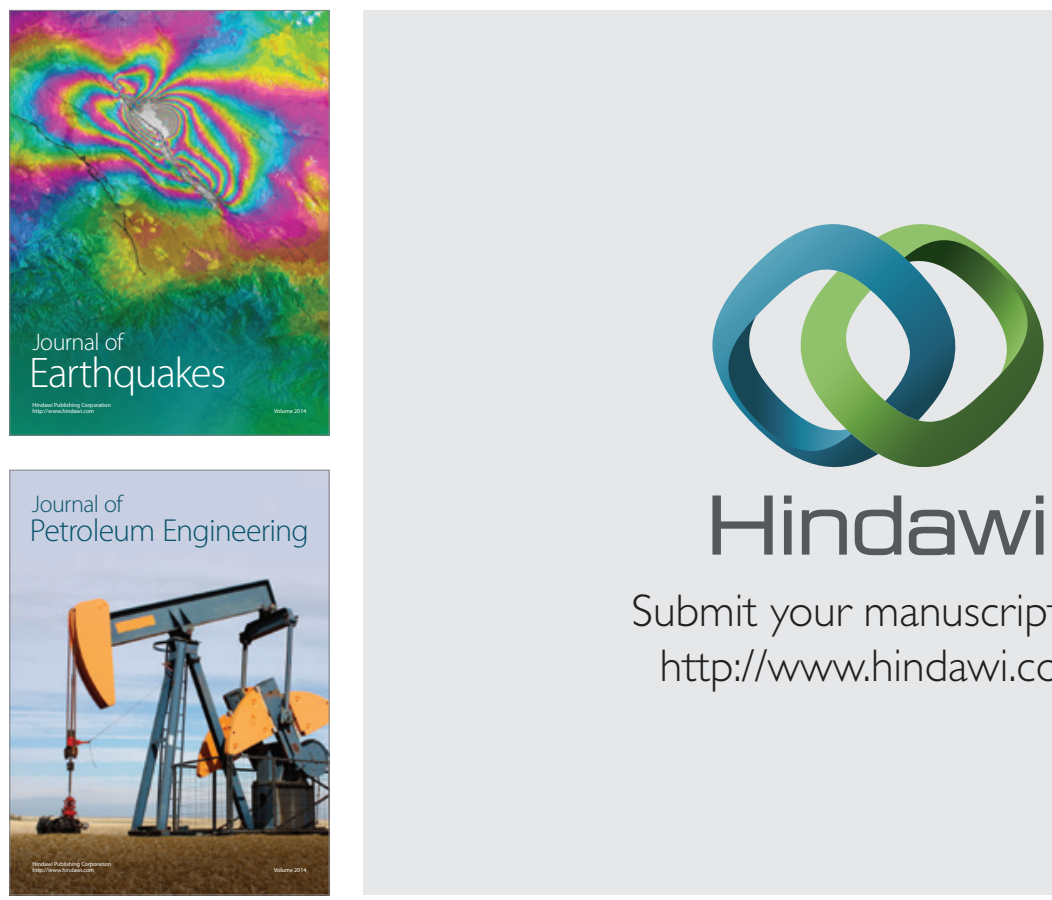

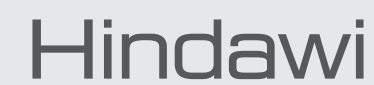

Submit your manuscripts at

http://www.hindawi.com
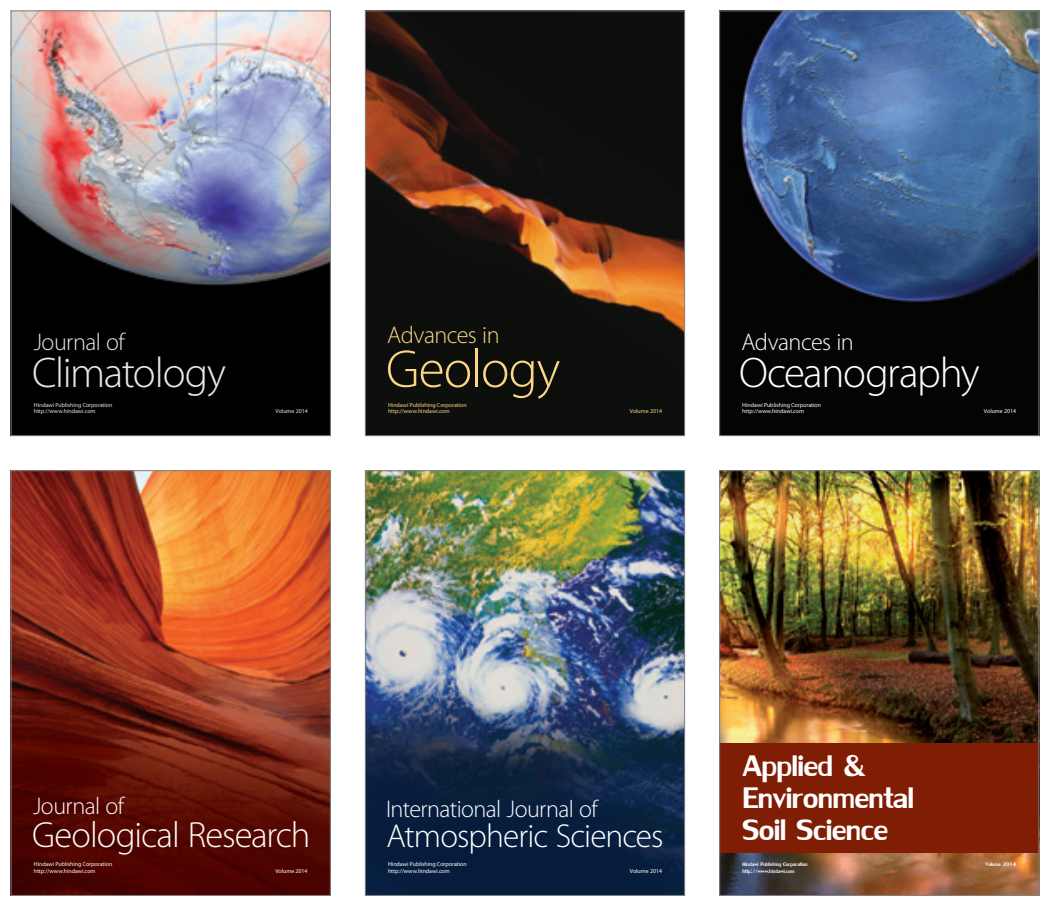
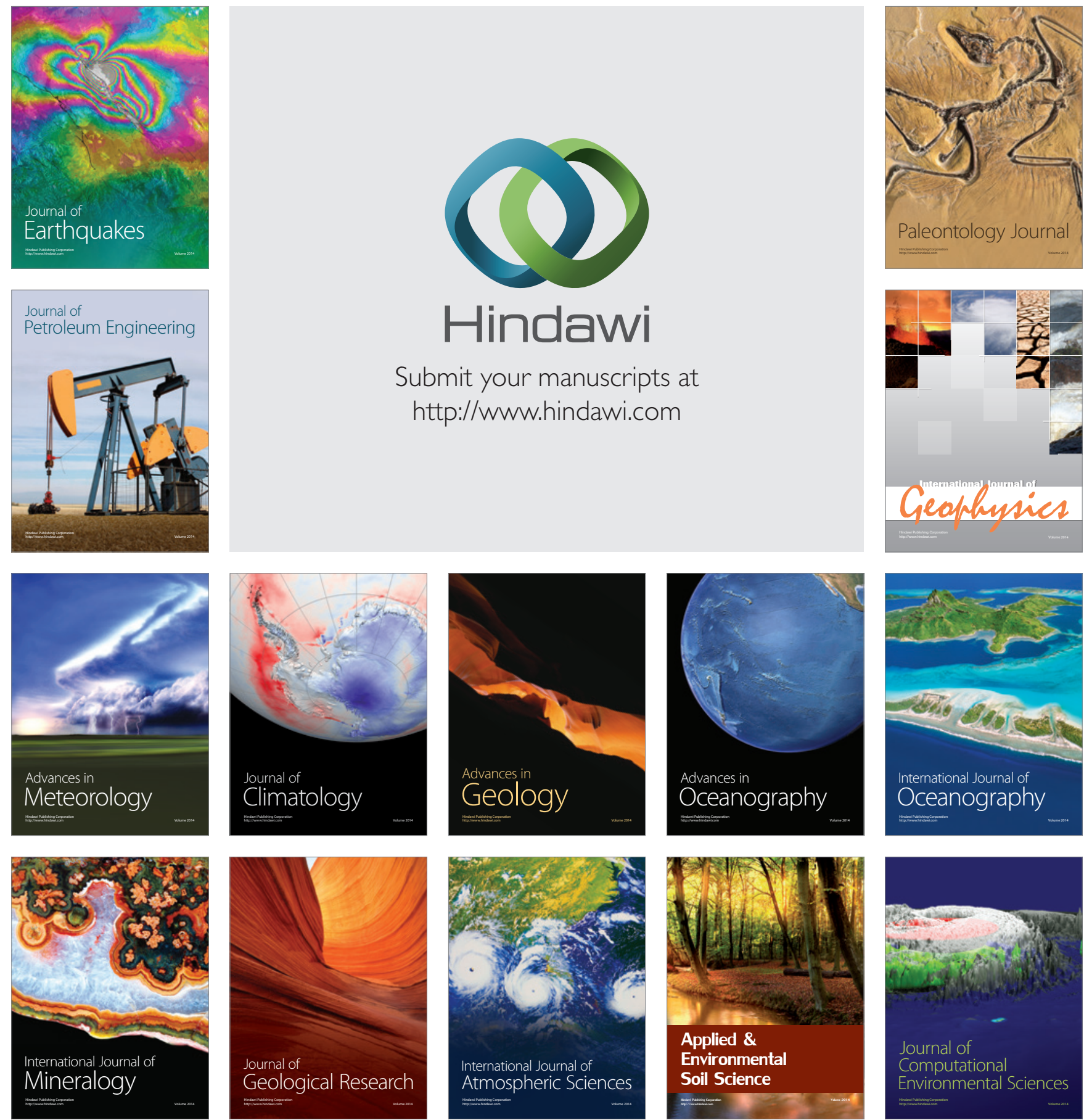